\title{
National natural rates of interest and the single monetary policy in the Euro Area
}

\author{
Sébastien Fries ${ }^{1}$, Jean-Stéphane Mésonnier ${ }^{2}$, Sarah \\ Mouabbi $^{3} \&$ Jean-Paul Renne ${ }^{4}$
}

\section{October 2017, WP \#611 (First version: December 2016)}

\begin{abstract}
We estimate time-varying national natural real rates of interest $\left(\mathrm{r}^{*}\right)$ for the four largest economies of the euro area over 1999-2016. We further derive the associated national real interest rate gaps, which gauge the perceived monetary policy stance in each country. We find that the average $r^{*}$ have been lower after 2008. Furthermore, national r* were significantly negative in Southern countries during the sovereign crisis. As their effective real rates soared, national rate gaps across the euro area diverged. However, a common policy stance has been restored since 2014 as the ECB's unconventional programs gathered pace. $^{5}$
\end{abstract}

Keywords: Euro area countries, natural rate of interest, common monetary policy, fragmentation. JEL classification: C32; E32; E43; E52.

\footnotetext{
${ }^{1}$ Crest, Paris-Saclay University (e-mail: sebastien.fries@ensae-paristech.fr)

${ }^{2}$ Banque de France (e-mail: jean-stephane.mesonnier@banque-france.fr)

${ }^{3}$ Banque de France (e-mail: sarah.mouabbi@,banque-france.fr)

${ }^{4}$ HEC Lausanne (e-mail: jean-paul.renne@unil.ch )

${ }^{5}$ We thank Jesper Linde (discussant), Julien Matheron, Pierre Sicsic, Jonathan Wright and one anonymous referee for useful comments and suggestions, as well as seminar participants at Banque de France, the European Central Bank, IAAE 2016 (Milano), SSES 2017 (Lausanne), OFCE and the Swiss National Bank. The views expressed herein are those of the authors and do not necessarily reflect those of the Banque de France or the Eurosystem.
}

Working Papers reflect the opinions of the authors and do not necessarily express the views of the Banque de France. This document is available on publications.banque-france.fr/en 


\section{NON-TECHNICAL SUMMARY}

The persistence of low growth and low long-term real interest rates in major developed economies in the aftermath of the Great Recession has prompted a vivid debate about a possible downward shift in the level of the equilibrium, or "natural" real rate of interest. The natural rate of interest, often denoted by $r^{*}$, is conceptually an important benchmark for monetary policy. It is commonly understood as the level of the medium-run real rate that equates investment and savings. Theories in support of a declining $\mathrm{r}^{*}$ have therefore pointed to the role of a series of possible factors, either structural or of more temporary nature, which may have exacerbated a situation of excess savings over the last decade. Some of these factors are likely to have a differentiated impact across the national economies in the euro area, thus potentially driving national natural rates apart. Diverging natural rates of interest across major economies of a monetary union would however represent a major threat for the conduct and efficiency of a common monetary policy. Despite the importance of this issue within the euro area, to date, measures of the national natural rate of interest in Member countries are still lacking.

\section{Figure 1: Smoothed trajectories of the national natural interest rates.}

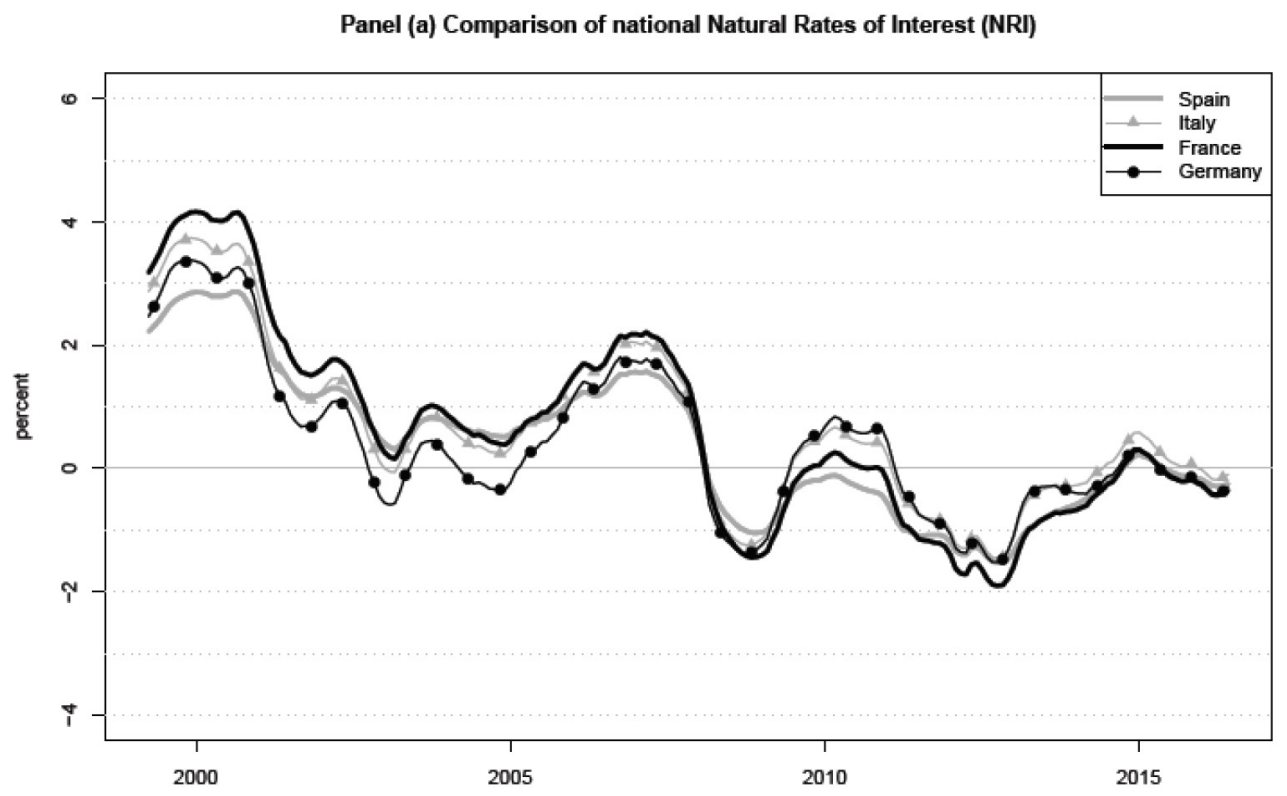

We define here the natural rate as the (one-year) real rate of interest which is consistent with output being at its potential once the effects of transitory demand and supply shocks have dissipated. Having in mind that any difference between output and its potential - i.e., the output gap - will impinge sooner or later on inflation, this is tantamount to defining the natural rate as the real rate consistent with stable inflation in the medium-run, a definition that obviously echoes the operational objective of many central banks today. As soon as the natural rate of interest moves, reflecting the influence of technology, time preference or other real exogenous shocks, there is then a clear case for a stabilityoriented monetary policy to try and track its fluctuations (see, e.g., Barsky et al., 2014). 
We estimate time-varying national natural rates of interest for each of the four largest economies of the euro area - France, Germany, Italy and Spain - since the inception of the euro in 1999. We filter these unobserved variables conditionally on a joint stylized model of these four economies and their interactions. We first find evidence of a common declining trend of the four national $\mathrm{r}^{*}$ over the last fifteen years. With the exception of a few short-lived episodes, the latest one being during the post-Lehman recession, differences in national $\mathrm{r}^{*}$ across countries remained relatively contained and generally below one percentage point. However, actual short-term (one year) real interest rates diverged markedly during the euro area sovereign crisis, reflecting the surge in the sovereign credit spreads of Southern countries. We then compute country-specific measures of the real interest rate gap, the difference between the local ex ante real rate and the estimated national natural rate. According to this metric, the single monetary policy failed to be unique across member countries over several episodes, most notably at the climax of the euro area crisis. While ensuring a neutral stance vis-à-vis core economies, it proved strongly dis-inflationary in Spain and Italy from mid-2011 to the end of 2012. Eventually, all four national real interest rate gaps converged to roughly $-1 \%$ over the years 2014-2016, witnessing a more consistent, expansionary single policy stance across the area, as the Eurosystem embarked more decisively on unconventional programs.

\title{
Taux d'intérêt naturel nationaux et politique monétaire unique dans la zone euro
}

\begin{abstract}
RÉSUMÉ
Nous estimons des séries de taux d'intérêt réel naturel $\left(\mathrm{r}^{*}\right)$ nationaux pour chacune des quatre plus grandes économies de la zone euro sur la période de 1999 à 2016. Nous en dérivons les mesures associées d'écart de taux d'intérêt réel au niveau national, qui quantifient l'orientation perçue de la politique monétaire dans chaque pays. Nous trouvons que les $\mathrm{r}^{*}$ sont en moyenne inférieurs après 2008. De plus, les $\mathrm{r}^{*}$ nationaux ont été significativement négatifs dans les pays du Sud pendant la crise de la dette souveraine. Les taux réels effectifs de ces pays montant en flèche au cours de cette période, les écarts de taux réels nationaux ont alors fortement divergé au sein de la zone euro. Cependant, l'orientation commune de la politique monétaire à travers les pays a été restaurée à partir de 2014, alors que les programmes non-conventionnels de la BCE gagnaient en intensité.

Mots-clés : Zone euro, taux d'intérêt naturel, politique monétaire commune, fragmentation.
\end{abstract}

Les Documents de travail reflètent les idées personnelles de leurs auteurs et n'expriment pas nécessairement la position de la Banque de France. Ce document est disponible sur publications.banque-france.fr 


\section{Introduction}

The persistence of low growth and low long-term real interest rates in major developed economies in the aftermath of the Great Recession has prompted a vivid debate about a possible downward shift in the level of the equilibrium, or "natural" real rate of interest (e.g., Hamilton et al., 2015; Laubach and Williams, 2015; Rachel and Smith, 2015; Holston et al., 2016). The natural rate of interest, often denoted by $r^{*}$, is conceptually an important benchmark for monetary policy. It is commonly understood as the level of the medium-run real rate that equates investment and savings. Theories in support of a declining $r^{*}$ have therefore pointed to the role of a series of possible factors which may have exacerbated a situation of excess savings over the last decade. ${ }^{1}$ Some of these factors are likely to have a differentiated impact across the national economies in the euro area, thus potentially driving national natural rates apart. Diverging natural rates of interest across major economies of a monetary union would however represent a major threat for the conduct and efficiency of a common monetary policy. Despite the importance of this issue within the euro area, to date, measures of the national natural rate of interest in Member countries are still lacking.

In this paper, we estimate time-varying national natural rates of interest for each of the four largest economies of the euro area - France, Germany, Italy and Spain - since the inception of the euro in 1999. We filter these unobserved variables conditionally on a joint stylized model of these four economies and their interactions. We first find evidence of a common declining trend of the four national $r^{*}$ over the last fifteen years. With the exception of a few short-lived episodes, the latest one being during the post-Lehman recession, differences in national $r^{*}$ across countries remained relatively contained and generally below one percentage point. However, actual short-term (one year) real interest rates diverged markedly during the euro area sovereign crisis, reflecting the surge in the sovereign credit spreads of Southern countries. We then compute country-specific measures of the real interest rate gap, the difference between the local ex ante real rate and the estimated national natural rate. According to this metric, the single monetary policy failed to be unique across member countries over several episodes, most notably at the climax of the euro area crisis. While ensuring a neutral stance vis-à-vis core economies, it proved strongly

\footnotetext{
${ }^{1}$ Some of these factors are more structural (e.g., the population aging, the rise in income inequalities in the developed world), others are more conjunctural (e.g., the forced deleveraging of households after the housing bust, or the aggressive fiscal retrenchments observed in some economies). See, e.g., Benigno, Eggertsson and Romei (2014) and Kocherlakota (2015) for the effects of public debt. Del Negro, Giannone, Giannoni and Tambalotti (2017) also highlight the role of the increased "convenience yield" associated with an excess demand for safe, liquid shortterm assets (like AAA government bonds) in explaining lower trend real interest rates. This "asset pricing" effect may however reflect underlying demographic trends and structural changes in the labor market.
} 
dis-inflationary in Spain an Italy from mid-2011 to the end of 2012. Eventually, all four national real interest rate gaps converged to roughly $-1 \%$ over the years 20142016, witnessing a more consistent, expansionary single policy stance across the area, as the Eurosystem embarked more decisively on unconventional programs. ${ }^{2}$

The concept of a natural rate of interest and its role as a benchmark for monetary policy dates back at least to Wicksell (1898[1936]), who defined it as the level of "the [real] rate of interest on loans which is neutral with respect to commodity prices and tends neither to increase nor to decrease them". After having vanished from macroeconomics textbooks for decades, the notion resurfaced as a central concept in the modern monetary policy toolbox at the beginning of the last decade, mostly due to the success of its reinterpretation by Woodford (2003) within the canonical New-Keynesian (NK) framework. In the NK framework, the natural rate of interest is the equilibrium real rate of interest in a counter-factual version of the economy without any nominal rigidities: the equilibrium rate is therefore equal to the natural one when output is equal to its fully-flexible-price equivalent. ${ }^{3}$ In a closely related, but less abstract strand, we define here the natural rate as the (one-year) real rate of interest which is consistent with output being at its potential once the effects of transitory demand and supply shocks have dissipated. Having in mind that any difference between output and its potential — i.e., the output gap — will impinge sooner or later on inflation, this is tantamount to defining the natural rate as the real rate consistent with stable inflation in the medium-run, a definition that obviously echoes the operational objective of many central banks today. As soon as the natural rate of interest moves, reflecting the influence of technology, time preference or other real exogenous shocks, there is then a clear case for a stability-oriented monetary policy to try and track its fluctuations (e.g., Barsky et al., 2014).

Over the last fifteen years, various econometric approaches have been proposed to estimate this unobserved variable, ranging from uni-variate statistical filters extracting unconditional trends of observed real interest rates to fully-fledged DSGE models. Following Laubach and Williams (2003) and Mésonnier and Renne (2007), among others, we strike a balance between these two extremes and follow a semistructural approach, whereby we use the Kalman filter to estimate the natural rate of interest as an unobserved variable which is conditional on a small dynamic, backward-looking macroeconomic model of the economy, but without explicit micro foundations. The advantages of following this approach are threefold. Firstly, the definition of the natural rate is economically intuitive and easy to interpret in

\footnotetext{
${ }^{2}$ These measures include explicit forward guidance in mid-2013, T-LTROs, CBPP and ABSPP in the Fall of 2014, EAPP in early 2015, i.e. the long-awaited large scale program of sovereign bond purchases, also known as QE.

${ }^{3}$ See Woodford (2003) or Gali (2008) for a detailed presentation of the natural rate of interest in the canonical NK model.
} 
terms of modern central banks' mandates. Notably, our natural rate tracks smooth changes in potential output growth in each country. Potential growth is in turn pinned down by the linear relationship between the output gap and the lagged real interest gap along the estimated IS curve, while the output gap is itself constrained to be consistent with future inflation along the estimated Phillips curve.

Secondly, we abstract from describing the reaction function of the central bank and model the observed ex ante (one-year) real rate of interest in each country as an exogenous variable. This is particularly convenient in the context of the recent years in the euro area, for two reasons. First, the conventional monetary policy instrument, the repo rate of the European Central Bank (ECB), has been constrained by its effective lower bound for several years now. ${ }^{4}$ Second, soaring sovereign credit spreads, after 2010, in crisis-hit countries have driven short-term nominal reference interest rates in these economies away from the policy rate. However, modeling credit spreads in a fully-fledged macro-financial set-up, which would notably entail the inclusion of national public finance variables in our dynamic framework, clearly goes beyond the scope of this paper. ${ }^{5}$ In our specification, we therefore assume that the real rate of interest which is relevant for the private sector's expenditures in each country is the one-year, ex ante domestic sovereign bond yield, deflated by inflation expectations of professional forecasters for this country. ${ }^{6}$

Thirdly, a semi-structural approach remains tractable in an open economy, multicountry set-up, even in the case of more than two countries. Compared to Mésonnier and Renne (2007), our main innovation is that we extend their framework to a joint model for the four largest economies in the euro area, instead of considering the area as a whole. In order to account for the high degree of economic integration between these four EMU Members, we assume that each national economy is linked to the other three via two channels: a trade channel and a productivity channel. First, the level of the output gap in each country depends on the external demand for national products in the other countries, which we capture by including the lagged foreign output gaps scaled by the share of the foreign partner in the country's exports. Second, we allow for cross-correlations of the shocks driving the (latent) trends

\footnotetext{
${ }^{4}$ Since October 2008 and the switch of the ECB's operational framework to a fixed-rate, fullallotment procedure, the effective policy rate has been the (lower) deposit facility rate and not the usual repo rate.

${ }^{5}$ Borgy, Laubach, Mésonnier and Renne (2011) provide an example of a joint modeling of the term structure of sovereign credit spreads of several euro area countries and discuss the associated technical challenges.

${ }^{6}$ Note that the level of this observed real rate reflects the level of both the current and forward expected policy rates over the next 12 months. It can thus account for any additional degree of monetary accommodation obtained by the implementation of unconventional measures at the zero-lower bound (such as explicit forward guidance, long-term refinancing operations or outright asset purchases).
} 
of national potential output growth. ${ }^{7}$ This specification is meant to capture the fact that these four economies have faced common shocks over the period, such as the liquidity dry-up of 2007-2008 and the trade collapse of 2009, but also that many national medium-sized and large firms have a regional outreach and that their output relies on transnational production chains within the area. Overall, we obtain a relatively parsimonious model of a simplified euro area made up of four countries, that we estimate by maximum likelihood.

Our estimation yields plausible and significant values for all key parameters, and notably the slopes of the Phillips and IS curves. We obtain time-varying measures of the unobserved, latent variables in the model: the national natural rates of interest and the derived interest rate gaps, the national output gaps and associated rates of potential output growth. We first find that the four national natural rates fluctuated widely around a globally declining trend over the last fifteen years, a result consistent with the findings of Holston, Laubach and Williams (2016). Cross-sectional averages indeed hovered between $3.5 \%$ in 2000 and $-1.5 \%$ in 2012, to finally reach a level close to, but below zero in 2016. Before the 2008 crisis, national $r^{*}$ also tended to increasingly co-move, as the cross-sectional dispersion declined from some $1.3 \%$ in 2000 to some $0.4 \%$ in 2007 . The worldwide financial crisis triggered by the collapse of Lehman brothers, and the ensuing recession, drove natural rates down in all four countries, to some $-1 \%$. Although they recovered rapidly thereafter, their trajectories diverged again to some extent in 2010 and 2011. National natural rates remained mostly in negative territory during the euro area sovereign debt crisis, reaching a trough in the second half of 2012, at nearly $-2 \%$ in France and around $-1.5 \%$ in the other three countries. National $r^{*}$ have eventually stabilized to slightly negative levels in all economies since mid-2015. Accordingly, since actual real one-year interest rates diverged markedly during the euro area crisis, estimated national interest rate gaps point to quite differentiated effective monetary policy stances across the four countries over the years 2011-2013. Overall, our estimates suggest that the single monetary policy has been almost neutral in France over the post-2009 period, while it had significantly restrictive effects in Italy and Spain in 2011-2012 and has been rather expansionary in Germany since 2013.

We contribute to three strands of the literature and current policy debates. First, our study provides an illustration of how to use the concept of natural interest rates to inform policymakers. Compared to previous studies, ours is the first to estimate natural rates for individual Member countries of the euro area in a consistent

\footnotetext{
${ }^{7}$ Note that we label these shocks trend productivity shocks for simplicity. However, as our model is reduced-form, these shocks may reflect any correlated shocks that bear on trend output growth. Simultaneous or even coordinated austerity shocks during the euro area sovereign debt crisis are a possible case.
} 
framework. $^{8}$ Our findings shed therefore a new light on the debate on the financial fragmentation of the area during the 2010s and the relevance of a one-size-fits-all monetary policy in this stressed environment characterized by the largely asymmetric shocks of the sovereign debt panic.

Second, our estimates of natural rates of interest for four large European economies also provide useful evidence for the on-going debate on low real rates after the crisis and the secular stagnation hypothesis (e.g., Eggertsson and Mehrotra, 2014). ${ }^{9}$ Most recently, Lewis and Vazquez-Grande (2017) claimed that the result of a declining $r^{*}$ put forward by Laubach and Williams (2015) hinges at their assumption that the non-growth factor driving the natural rate is non-stationary. In contrast, Lewis and Vazquez-Grande (2017) find evidence of some return to pre-crisis levels under alternative assumptions. Although we assume here that the national natural rates are stationary variables, we find confirmation that, after the crisis, they remain well below their pre-crisis levels.

Last, our study also provides relevant insights into the relation between structural reforms and monetary policy in Europe (e.g., Pesenti, 2015). When an economy is hit by a series of negative shocks on its natural interest rate and monetary policy is constrained by its effective lower bound, structural reforms that have short-term deflationary effects can delay the return to growth and even trigger a vicious cycle of disinflation, low demand, and further disinflation, which pushes the interest rate gap up and the output gap down, with possible hysteresis effects (e.g., Eggertsson et al., 2014).

The rest of this paper is organized as follows. Section 2 presents our stylized joint model for the four largest euro-area economies. Section 3 describes the data and details our estimation procedure. Section 4 discusses our results. Robustness checks are presented in Section 5 while Section 6 concludes.

\section{Model}

We jointly model the dynamics of the four largest economies of the euro area using a parsimonious set-up with unobserved variables that we want to estimate. The fourcountry area as a whole is modeled as a closed economy, but each of the four member countries is allowed to interact with the other three and is therefore modeled as an open economy under a fixed exchange rate regime.

\footnotetext{
${ }^{8}$ Bouis, Rawdanowicz, Renne, Watanabe and Christensen (2013) provide estimates of timevarying natural rates along the lines of Mésonnier and Renne (2007) for several developed economies but they consider the euro area as a whole and do not look at national developments within the EMU. More recently, Beyer and Wieland (2017) estimate $r^{*}$ for Germany and the euro area using the Laubach and Williams (2003) model but do not investigate growth and $r^{*}$ developments in other European countries.

${ }^{9}$ For a useful survey, see also Rachel and Smith (2015).
} 
More specifically, each national economy is summarized by the intersection of a dynamic supply -or Phillips- curve and a dynamic demand -or IS- curve. Both curves are backward-looking in nature, as in Rudebusch and Svensson (1999), Laubach and Williams (2003) and their followers, which makes the estimation of the unobserved variables of interest more tractable. Note that, as we do not use our model for policy simulations but only for providing an a posteriori assessment of the monetary policy stance in these countries, this is not a major shortcoming in theory. Besides, the available evidence for Europe suggests that backward-looking Phillips curves fit the data better than forward-looking ones. ${ }^{10}$

The Phillips curve in country $j$ therefore reads:

$$
\pi_{j t}=\mu_{j}^{\pi}+\gamma_{j} \pi_{j, t-1}+\beta_{j} z_{j, t-1}+\epsilon_{j t}^{\pi},
$$

where $\pi_{j t}$ denotes monthly (annualized) core HICP inflation and $z_{j t}$ denotes the output gap. We denote by $\epsilon_{j t}^{\pi}$ the residual cost-push shock, which is assumed to be a Gaussian white noise with standard deviation $\sigma_{j}^{\pi}$.

In turn, the output gap is a persistent variable which is determined along an IS curve by a linear relationship with the lagged real interest rate gap:

$$
z_{j t}=\alpha_{j} z_{j, t-1}+\delta_{j} \sum_{k=1}^{n} \chi_{j k} z_{k, t-1}+\lambda_{j}\left(i_{j, t-2}-\mathbb{E}_{t-2}\left[\pi_{j, t-2, t-2+h}\right]-r_{j, t-2}^{*}\right)+\epsilon_{j t}^{z}
$$

In this equation, $i_{j t}$ represents the country-specific, one-year nominal interest rate, which we measure as the yield-to-maturity of one-year domestic sovereign bonds. This yield is the sum of a risk-free, one-year rate, which reflects expected future policy rates up to 12 months ahead, and a credit and liquidity spread. We choose not to model explicitly the reaction function of the ECB, nor the dynamics of sovereign spreads. We therefore consider each $i_{j t}$ as an exogenous variable in the estimation process. We deflate this nominal rate using survey-based inflation expectations at the one-year horizon, $\mathbb{E}_{t}\left[\pi_{j, t, t+h}\right]$ (with $h=12$ at monthly frequency). Last $r_{j t}^{*}$ is the natural rate of interest that we want to estimate. The additional term accounts for the strong economic integration of the four largest euro-area economies. Intuitively, the output gap in country $j$ depends on the external demand of domestic goods by its trade partners $k$ within the area. In the spirit of a global VAR model (see Pesaran et al., 2004), we therefore assume that it is driven by a weighted average of lagged output gaps in partner countries, where the relative weights reflect the relative shares $\chi_{j k}$ of these countries in country $j$ 's exports.

The remaining equations of the model make explicit the definition and the dy-

\footnotetext{
${ }^{10}$ See for instance Rudd and Whelan (2007) and Mavroeidis, Plagborg-Moller and Stock (2014) for more insights on the NKPC debate.
} 
namics of the unobserved variables we want to estimate. First, the national output gap in country $j$ is simply the deviation of $\log$ (quarterly annualized) real GDP, $y_{j t}$ from its potential, denoted $y_{j t}^{*}$ :

$$
y_{j t}=y_{j t}^{*}+z_{j t}
$$

Second, we define the national natural rate in each country as in Mésonnier and Renne (2007):

$$
r_{j t}^{*}=\mu_{j}^{r}+\theta_{j} a_{j t},
$$

where $a_{j t}$ is a persistent process that also drives the low-frequency fluctuations in the country's potential growth. Indeed, $\Delta y_{j t}^{*}$, the growth rate of national potential output, is defined as:

$$
\Delta y_{j t}^{*}=\mu_{j}^{y}+a_{j t}+\epsilon_{j t}^{y},
$$

where $\mu_{j}^{y}$ is a constant and $\epsilon_{j t}^{y}$ a Gaussian white noise of standard deviation $\sigma_{j}^{y}$.

The intuition behind our specification for the natural rate is provided by the textbook neoclassical growth model, where the real equilibrium rate of interest is an affine function of the balanced growth path for real (per capita) consumption. ${ }^{11}$ For simplicity, we refer to $a_{j t}$ in what follows as the underlying productivity trend in the economy. However, one should keep in mind that our approach to estimate the natural rate is reduced form and that we cannot disentangle between the various drivers of the real equilibrium rate of interest in each country (e.g., technology shocks, fiscal shocks, changes in the rate of time preference or population growth, exogenous changes in households debt limit etc., depending on the precise theoretical model one has in mind). ${ }^{12}$ Adding the $\epsilon_{j t}^{y}$ term to the determinants of potential growth therefore offers some flexibility and allows to accommodate for possible exogenous disturbances that may have differentiated effects on the natural rate of interest and potential output growth (e.g., changes in households' rate of time preference).

This country-specific "productivity trend" is assumed to follow an AR(1) process:

$$
a_{j t}=\psi_{j} a_{j, t-1}+\epsilon_{j t}^{a}
$$

where $\left|\psi_{j}\right|<1$ is the autoregressive coefficient and $\epsilon_{j t}^{a}$ is a Gaussian white noise with standard deviation $\sigma_{j}^{a}$. Note here that we allow $\epsilon_{j t}^{a}$ to be correlated across

\footnotetext{
${ }^{11}$ Typically, $r_{j t}^{*}=\rho_{j}+\theta_{j} c_{j t}^{*}$, where $\rho_{j}$ is the rate of time preference of households and $\theta_{j}$ is their risk aversion parameter.

${ }^{12}$ Note that several candidate factors, including demographic ones, are very slow moving and thus unlikely to be disentangled from deterministic trends over a relatively short time span of 17 years.
} 
countries, with correlation matrix $\Sigma$, while the other shocks are assumed to be crosssectionally independent. We therefore explicitly account for correlated productivity shocks across euro-area countries.

Note that our specification departs from the influential Laubach and Williams (2003) model (LW in short) and its recent updates, see Holston, Laubach and Williams (2016) along two important dimensions. First, in our approach, $r^{*}$ is driven by just one growth-related factor $\left(a_{t}\right)$, and not by the sum of this growthrelated factor and of an additional unobservable, non-growth-related variable (which can for instance be interpreted as reflecting changes in consumers' time preference), e.g.: $r_{j t}^{*}=\theta_{j} a_{j t}+\zeta_{j t} .{ }^{13}$ Second, we assume the growth-related factor to be stationary.

The reasons why we make these choices are again twofold. First, the LW model turns out to be very difficult to estimate in the case of the euro area, in particular under the assumption of non-stationary factors, as Beyer and Wieland (2017) also recently pointed out. Besides, even when convergence is achieved, the non-growth factor $\zeta_{j t}$ turns out to be quite imprecisely estimated. ${ }^{14}$ Second, the short time-span since the inception of the euro makes it less appropriate to model trend potential output growth as a non-stationary process. Furthermore, our estimation yields estimates of the auto-regressive coefficients $\psi_{j}$ that are clearly below unity, which tends to vindicate our assumption. Last, another practical advantage of our specification is that it offers a simple and transparent way to initialize the Kalman filter when it comes to estimating the model (see the estimation section below and the online appendix for further details).

\section{Data and estimation}

\subsection{Data}

Our data set covers the period from January 1999 to June 2016 at a monthly frequency for the four largest euro-area economies, France, Germany, Italy and Spain. We use national series of real GDP and the industrial production index (IPI) from Eurostat, and national series of the harmonized index of consumer prices excluding energy (core HICP) from the ECB. Real activity data are seasonally adjusted by Eurostat. Given not all core HICP series are seasonally adjusted in the ECB SDW

\footnotetext{
${ }^{13} \mathrm{LW}$ use different notations: $r_{j t}^{*}=c_{j} g_{j t}+z_{j t}$. Since we denote in our case the output gap with $z$, we adapt here the notations to our context for clarity.

${ }^{14}$ This is duly acknowledged by Holston, Laubach and Williams (2016). A closer look at their results for the euro area, which can be replicated using their codes and data made available on-line, confirms that the estimated $\zeta_{e a, t}$ is indeed never significantly different from zero at conventional levels of confidence. Note that this conclusion holds whatever the calibrated value of $\theta$, the coefficient of the growth-related factor in the $r^{*}$ equation (be it either 1 as in LW, or 4, close to our baseline and identical to the calibration in Mésonnier and Renne (2007)) .
} 
database, we adjust two of them, the German and Spanish ones, using the TramoSeats procedure. All growth rates in what follows are defined in logarithms. Our measure of the one-year reference nominal interest rate in each euro area country is the yield of one-year domestic sovereign bonds, taken from Datastream. We derive national ex ante one-year real interest rates $\left(r_{j t}\right)$ from this national nominal rate by subtracting national measures of inflation expectations at a one-year horizon. We use national forecasts published by Consensus Economics for the current and subsequent years, and interpolate them linearly in order to construct fixed-horizon inflation forecasts.

Before embarking on the presentation of estimation details, we briefly sketch here the main patterns in the series used as inputs. ${ }^{15}$ Interestingly, inflation rates were quite heterogeneous across the large euro-area countries before the financial crisis, while they have moved more in synch thereafter. Indeed, the pre-crisis inflation gap between Spain, the most inflationary country, and Germany, the least inflationary country over this period, ranges between 1 and 3 percentage points (year-on-year), with a peak reached at the end of 2002. After the global financial crisis and along with the aggravation of the sovereign debt crisis in Southern Europe, inflation has tended to decline more rapidly in Spain and Italy than in the core economies. Consistently with the view that pre-crisis GDP growth was fueled by sustained excess demand in Southern countries, this pattern of relative inflation rates is reflected by the pattern of relative growth rates of real GDP, with faster growth rates in Spain before 2007, but higher growth rates in Germany after the 2009 trough, France and Italy hovering between the two extremes. Last, although the Spanish one-year ex ante national real interest rates were consistently below other countries' rates over the first decade of the euro area, the dispersion of national real rates across economies unsurprisingly reached unprecedented levels during the euro area sovereign crisis in 2011-2013. Real sovereign rates in core economies globally followed a downward trend from the beginning of the 2000s to their trough of 2012, at roughly $-2 \%$, reflecting the long sequence of nominal policy rate cuts following the outburst of the financial turmoil in the Fall of 2008. However, with the outburst of the sovereign crisis, real rates in the two Southern economies rocketed up to 4 percentage points above their Northern equivalents. Effective real interest rates in the core countries rose markedly again in 2013 and 2014, reflecting the continued fall in one-year inflation expectations over this period. Finally, in all four countries, real rates receded again in 2015 and 2016 to remain contained between $-2 \%$ and $-1 \%$, a possible effect of the reinforced forward guidance introduced by the numerous unconventional measures implemented by the Eurosystem in 2014 (T-LTRO, ABSPP) and $2015(\mathrm{QE})$.

\footnotetext{
${ }^{15}$ To save space, a figure showing our data set is left for the online appendix
} 


\subsection{Estimation}

Our model of the euro area includes two unobserved variables, $a_{j t}$ and $z_{j t}$, and two observed variables, monthly inflation $\pi_{j t}$ and quarterly GDP $Y_{j t}^{Q}$, for each of the four largest countries. ${ }^{16}$ We rewrite the model in state-space form and apply the Kalman filter to recover measures of the unobserved variables conditional on parameter estimates that we obtain by maximum likelihood. Note that we estimate measures of the unobserved variables with monthly frequency, while one of our two observed variables, real GDP, is observed with quarterly frequency only. The issue of missing data is handled by slightly adjusting the standard Kalman filter as suggested by Harvey and Pierse (1984). Nevertheless, as our sample is relatively small, relying only on quarterly GDP data to measure real activity implies a substantial loss in estimation precision. We therefore increase our information set and add for each country a third measurement equation linking unobserved monthly GDP growth with the observed growth in IPI. ${ }^{17}$

Estimating the complete model with the Kalman filter entails some technical choices. These choices relate notably to the calibration of some parameters, the initialization of the Kalman filtering of the unobserved factors conditionally to a given set of the parameters that remain to be estimated and, last but not least, the initialization of the optimization algorithm that yields ML estimates of the non-calibrated parameters and the final estimate of the factors. We briefly explain below our main choices regarding the calibration of some parameters, leaving detailed explanations on the initialization of the likelihood maximization and Kalman filtering algorithms for the online appendix.

Some parameters are notoriously difficult to estimate in such a set-up and we calibrate them following notably Mésonnier and Renne (2007) and Bouis, Rawdanowicz, Renne, Watanabe and Christensen (2013), as summarized in Table 1. The most important calibrations relate to the process driving the natural rate of interest $r_{j t}^{*}$.

First, we calibrate the parameter $\theta_{j}$, which links the unobserved natural rate to the unobserved trend productivity growth in country $j$ and is akin to households' risk aversion coefficient in a simple model. To the best of our knowledge, no study provides with estimates of this structural parameter for all four coun-

\footnotetext{
${ }^{16}$ Note that the model is linear but not closed, as we do not specify the reaction function of the ECB and take the effective ex ante one-year real interest rate in each country as exogenous. To check for the model's plausibility, we nevertheless ran an additional exercise where we added a Taylor-type monetary policy rule for the one-year risk-free nominal rate (assuming exogenous sovereign spreads) and computed impulse responses to a monetary policy shock. In spite of the inherent limits (regarding notably the assumption of a linear monetary policy rule at the zero lower-bound), obtained IRFs behave roughly as expected.

${ }^{17}$ Formally, we use the IPI growth rate as an affine proxy of the GDP growth rate: $\Delta_{j t}^{\mathrm{IPI}}=$ $\mu_{j}^{\mathrm{IPI}}+\varphi_{j} \Delta y_{j t}+\epsilon_{j t}^{\mathrm{IPI}}$. Refer to the online appendix for further details.
} 
tries in a consistent framework. We therefore combined recent estimates of $\theta$ for France and information about households' participation rates into risky assets in euro-area countries from the 2010 Eurosystem's Household Finance and Consumption Survey (HFCS). Since the seminal contribution of Friend and Blume (1975), researchers have indeed commonly implemented a revealed preference strategy and inferred households' risk aversion from the share of risky assets, such as stocks, in their financial wealth or from the observed participation rates of households into risky assets. More precisely, we proceed as follows. We first consider Arrondel and Savignac (2015)'s recent estimates of households' risk aversion for France, which they infer from a simple two-stage lottery included in the French National Statistical Institute's 2010 Wealth Survey. Their findings suggest a value of 3.5 for $\theta_{F R}{ }^{18}$ Taking this value as a benchmark, we derive risk aversion values for the remaining countries by simply assuming that there is a linear relationship between local risk aversions and countries' shares of households not holding stocks. ${ }^{19}$ Interestingly, we end up getting quite similar values of $\theta$ across countries, ranging from 3.5 in France to 3.7 in Spain and Germany and 3.9 in Italy. Note that these values are very close to the baseline calibration of $\theta=4$ for the euro area as a whole in Mésonnier and Renne (2007). ${ }^{20}$ We nevertheless check in the robustness section below that our main conclusions remain valid when the $\theta_{j}$ take other plausible values.

Second, we assume that in each country the variance of the natural interest rate is equal to half the sample variance of the effective, ex ante, real interest rate. ${ }^{21}$

Remaining calibrations relate to, first, the constants $\left(\mu_{j}^{r}\right),\left(\mu_{j}^{y}\right)$ and $\left(\mu_{j}^{\pi}\right)$, and second, the signal-to-noise ratios $\sigma_{j}^{z} / \sigma_{j}^{y}$. For each country, the first two constants are respectively calibrated to the unconditional means of the ex ante national real rate of interest and GDP growth. Inflation series are demeaned before estimation, which is tantamount to calibrating $\left(\mu_{j}^{\pi}\right) /(1-\gamma)=\bar{\pi}_{j}$, where $\bar{\pi}_{j}$ is the unconditional mean of inflation.

\footnotetext{
${ }^{18}$ The outcome of their estimation under the assumption of risk-averse, CRRA preferences is in fact a range measure in four brackets: $58 \%$ of respondents are extremely risk averse $(\theta>3.76)$, $27 \%$ very risk averse $(2<\theta<3.76), 10 \%$ are moderately risk averse $(1<\theta<2)$ and only $5 \%$ are risk lovers $(0<\theta<1)$. Assuming a maximum of $\theta=5$ and taking the average of mid-range values weighted by the shares of respondents in each bracket, we find an estimate of $\theta_{F R}=3.5$.

${ }^{19}$ According to the 2010 HFCS, around $10 \%$ of German and Spanish households held stocks, compared to roughly $15 \%$ of French households and only $5 \%$ of Italian ones. We adjust these measures for differences in countries' participation rates in financial assets: our "shares of households not holding stocks" are, specifically, the fractions of households not holding shares among those households holding financial assets of any kind.

${ }^{20}$ These values are also plausible considering available estimates of risk aversion from several micro-econometric studies for the US and other advanced economies, that range between 0 and 5 . See references in Mésonnier and Renne (2007) for details.

${ }^{21}$ Formally, we impose for each country $j, \mathbb{V}\left(r_{j t}^{*}\right)=0.5 \mathbb{V}_{\text {sample }}\left(r_{j t}\right)$. Given our specification of the natural interest rate, this entails a constraint on the standard deviation of $\left(\epsilon_{j t}^{a}\right)$, namely that: $\sigma_{j}^{a}=\frac{\sqrt{0.5\left(1-\psi_{j}^{2}\right) \mathbb{V}_{\text {sample }}\left(r_{j t}\right)}}{\theta_{j}}$.
} 
Furthermore, we impose for all countries the uninformed prior that $\sigma_{j}^{z} / \sigma_{j}^{y}=$ 1. However, we need to deal appropriately with the secular drop in output that occurred over 2008Q4-2009Q1 as a consequence of the financial turmoil triggered by the collapse of Lehman Brothers on September 15, 2008. Ignoring the "catastrophic" nature of this event (which implied a drop in activity beyond five standard deviations of quarterly GDP growth over the life of the euro) indeed strongly impinges on our estimates of the unobservable variables in the aftermath of the Lehman bankruptcy, with notably estimated national $r^{*}$ plummeting to very low levels (between $-6 \%$ and $-8 \%$ ) at the end of 2008, and then quickly resuming. Such a deep and temporary fall in the estimated $r^{*}$ is very difficult to rationalize as reflecting true movements of the unobserved $r^{*}$ over this short period of time. We therefore neutralize the temporary direct impact of the Lehman panic on our estimates by allowing the algorithm to consider the possibility of larger shocks than usual to both the output gap and potential output growth during the first two quarters following the Lehman episode. More precisely, during these six months, the country-specific standard deviation parameters $\sigma_{j}^{z}$ and $\sigma_{j}^{y}$ are pre-multiplied by a country-quarter-specific "catastrophe factor", which is calibrated by the ratio of GDP growth in this quarter to the standard deviation in GDP growth over all quarters since 1999 except the Lehman episode.

Last we also calibrate the international trade weights $\chi_{j k}$ as the average export share of destination country $k$ over the period from 2000 to 2015 in the exports of country $j$ towards the other three countries in the EMU4 (see Table 2 for details). Nevertheless, we checked that our main results remain qualitatively unchanged when we impose that the key calibrated parameters take alternative reasonable values (refer to Section 5 below).

\section{Results}

Table 3 reports estimation results for the four countries under our baseline model specification. Key parameters, such as the slopes of the Phillips-curve $\beta_{j}$ and the slopes of the IS curve $\lambda_{j}$ are significant and have the expected sign (i.e. a positive $\beta_{j}$ and a negative $\lambda_{j}$ ). On average across countries, these parameters are of similar magnitude as the corresponding parameters estimated for the euro area as a whole over the period 1979-2004 by Mésonnier and Renne (2007). ${ }^{22}$ However, we find a sizable heterogeneity across countries for some parameters. Notably, the slope of the Phillips-curve is the largest in France (0.36), intermediate in Germany and Italy

\footnotetext{
${ }^{22}$ These slopes are however somewhat steeper in absolute terms than the slopes estimated by Laubach and Williams (2003) for the United States over the period 1961-2002 as well as the ones obtained by Holston, Laubach and Williams (2016) for the euro area over 1972-2015.
} 
(between 0.20 and 0.26 ) and the smallest in Spain (0.08). In contrast, the slope of the IS curve (the interest rate gap semi-elasticity of the output gap) is roughly the same in all four countries, slightly below -0.10 . The parameters governing the degree of persistence of the natural rates of interest, $\psi_{j}$, are between 0.91 and 0.95 across countries, with very tight standard deviations, which corroborates our choice of stationary processes for the $a_{j t}$.

Furthermore, Table 4 reports our estimates of the correlation matrix of the national trend productivity shocks $a_{j t}$. These unobserved variables come out as quite correlated, consistently with the strong co-movement of observed GDP growth series across the euro area's main economies since 1999. Specifically, the correlation coefficient is the highest (0.96) between France and Italy. It remains high, at 0.93, between Italy and Germany. In contrast, shocks to the Spanish trend productivity growth appear to co-move quite strongly with France's and Italy's, while being much less correlated with developments in Germany (correlation of 0.72).

The upper panel of Figure 1 provides an overview of the estimated natural rates of interest for the four countries, while the lower panels display each country's natural rate separately, along with the associated 95\% confidence bands. Note that confidence intervals account here for total uncertainty, i.e. filtering uncertainty (surrounding estimates of unobserved variables conditional on given parameters) compounded by estimation uncertainty (surrounding parameter estimates themselves). We compute the corresponding standard deviations using Hamilton (1986)'s Monte Carlo method. ${ }^{23}$

According to our estimations, the national natural rates of interest in the EMU4 economies fluctuated widely since the start of the euro, with individual values ranging between some $+4 \%$ in $2000-2001$ and $-2 \%$ in the last quarter of 2012 , at the climax of the euro area sovereign crisis. Our sample, which covers the lifespan of the euro area, is split in two equal parts by the outburst of the financial turmoil in late 2008. A comparison of pre-2008 with post-crisis levels shows that national natural rates were on average higher before the Great Recession. Before the Lehman bankruptcy indeed, they hovered around $1.3 \%$ while they remained on average well below this threshold between 2010 and 2015. ${ }^{24}$ This finding is in line with views that the trend decline in real interest rates over the last few decades also reflects a downward trend in real equilibrium rates in developed economies (e.g., Laubach and Williams, 2015; Holston et al., 2016). Last, the dispersion of natural interest rates across the four major economies of the euro area increased somehow in the years following the 2008-2009 recession, but the trend towards less cross-sectional

\footnotetext{
${ }^{23}$ See the online appendix for details.

${ }^{24}$ The average of the four national natural rates over $2009-2015$ is $-0.5 \%$, against $0.5 \%$ over 1999-2016.
} 
dispersion that was observed before 2008 resumed after 2014. While still in negative territory, national $r^{*}$ eventually converged close to $0 \%$ in the first semester of 2016 .

Beyond this broad picture, the confidence intervals around each country-specific estimates shown in Figure 1 allow to shed light on episodes when national natural rates were significantly different from zero. We find that national natural rates were significantly positive in all countries over the first few years of the EMU and in 2006-2007. They plummeted to low negative levels everywhere during the 2008-2009 recession, but resumed rapidly thereafter. After mid-2009 and up to the outburst of the euro area sovereign crisis, national natural interest rates stayed close to zero in all economies. They nevertheless dropped significantly below zero in the two Southern economies when the sovereign debt crisis escalated from mid-2011 onward, down to about $-1.5 \%$ in the second semester of 2012 , and remained significantly negative until the end of 2012 in Italy and mid-2013 in Spain.

A key advantage of our approach is that, since we estimate all four national natural rates jointly within the same model, we can deepen the analysis and further identify episodes of statistically significant divergence of national natural rates across these economies. $^{25}$ The upper-right panel of Figure 4 shows bilateral natural rate spreads together with $95 \%$ confidence intervals. We find that the natural interest rates in France, Germany and Italy have never been statistically different from each other since the start of the EMU. The bilateral $r^{*}$ gap widened quite a bit between Germany and Spain in the aftermath of the 2008-2009 financial crisis, reaching 1\% at the end of 2010, but even so it remained non-significant at the $5 \%$ level.

The natural interest rate is a key benchmark for monetary policy but it is not in itself an indicator of the monetary policy stance. As embedded in our model, the relevant stance indicator is the real interest rate gap, here the difference in each economy between the one-year ex ante (credit risk-free) real interest rate and its natural counterpart: a positive real rate gap tends to dampen excess demand and drive down the output gap, which ultimately transmits into lower inflation. Soaring credit spreads (during the sovereign crisis) and heterogeneous inflation dynamics (over the 2000s) contributed to drive national ex ante real interest rates apart over some periods of time, while national $r^{*}$ kept broadly co-moving in synch. As a consequence, differences between national real interest rates largely translated into differences between the monetary policy stances faced by each country.

Figure 2 shows our estimates of the national real interest rate gaps for the four countries and displays each country's natural rate separately, along with the associated $95 \%$ confidence bands, while Figure 3 presents the estimated national output

\footnotetext{
${ }^{25}$ The computation of confidence bounds around cross-country spreads of $r^{*}$ and IRG is based on the time-varying covariance matrix of the latent factors, which is yielded by the Kalman smoother algorithm.
} 
gaps. Figure 2 reveals a persistent negative national rate gap, i.e. an expansionary monetary stance, in Spain over most of the years 1999-2007, which is consistent with the widening positive output gap measured in this country over the same years (refer to Figure 3). Italy also experienced a long period of economic expansion before the crisis, but the contribution of the monetary stance to this sustained positive output gap seems to be more limited: while the real rate gap was significantly negative in this country in the early years of the euro, it closed as soon as 2002 and remained not significantly different to zero most of the time and up to the outburst of the global financial crisis. This suggests that other forces were at play in Italy and contributed to this sustained excess demand, such as an expansionary fiscal policy and a dynamic external demand from euro area partners.

The figures also confirm that the monetary policy stance was relatively recessionary across the board during the financial crisis of 2008-2009, as the gradual policy rate cuts and the accompanying liquidity provision measures failed to accommodate rapidly enough the unprecedented drop in national natural interest rates. Interest rate gaps indeed soared during the intensification of the financial crisis in 2008, peaking around 3.5\% in Germany and France, against about 3\% in Italy and $2 \%$ in Spain. This involuntary tightening contributed to decreasing national output gaps in 2009, well below zero in core countries and Italy, and closer to neutrality in Spain. The slightly negative interest rate gaps achieved in 2010-2011 eventually fueled a short-lived recovery in the two core economies and Italy. However, as the euro area sovereign crisis escalated in 2011, the soaring credit spreads, the deflationary forces at play and the falling natural rates contributed to imposing a significantly restrictive monetary stance on the two Southern economies over 2011-2013, while neutrality was broadly achieved and maintained in the two core countries. Last, the latter two enjoyed quite an expansionary monetary policy stance as the ECB embarked more vigorously on forward guidance and QE from 2014 onward.

Did the effective monetary policy stance significantly diverge across the four major countries of the euro area? If yes, when and to what extent? Again, our estimation procedure allows us to derive confidence intervals around our point estimates of the bilateral spreads between national interest rate gaps. The lower-left panel of Figure 4 shows these spreads since 1999. The figure confirms that the common monetary policy proved significantly more expansionary in Spain than it was in France and Germany, and even in Italy, over the period from 2002 to 2006, but then became significantly tighter than in Germany over most of the period from 2010 to 2015. With regard to the relative situation of Italy, this country also enjoyed a more expansionary monetary policy stance in 2003-2005 relative to Germany (but not to France), but it faced a significantly more restrictive one for about one year in 2011-2012. To sum up, while Spain was singled out before the financial crisis as 
benefiting from a more expansionary monetary stance than other countries due to its higher inflation and lower effective real rates, the sovereign debt crisis in 20112013 entailed a fragmentation of the euro area between North and South in terms of the effective monetary policy stance: the ECB policy achieved neutrality in core economies, but it was still too tight in the South.

Eventually, all interest rate gaps converged to a rather expansionary stance at the end of our sample, with point estimates between $-1.5 \%$ in Germany and $-0.8 \%$ in the Southern economies in June 2016. The return to a common, accommodative monetary stance across all four major euro-area economies can therefore be viewed as vindicating the success of the unconventional monetary policies implemented since 2013 in fighting the fragmentation of monetary and financial conditions in the area. This said, our point estimates of national output gaps in June 2016, which range from significantly negative values of $-5.3 \%$ in Spain and $-4.1 \%$ in Italy to an insignificant $-0.8 \%$ in France and a slightly positive gap of $0.4 \%$ in Germany, suggest that more macroeconomic stimulus was still needed at that time at least in Southern economies, while the substantial heterogeneity in economic conditions and fiscal space may limit the room for coordinated action.

\section{Robustness}

To what extent should we believe in our estimates? Elements in support of our findings are twofold. First, our estimates of unobserved variables are of reasonable orders of magnitude. Figure 5 shows a measure of the euro area natural rate of interest which we compute as the GDP-weighted average of our four national estimates (together with its $95 \%$ confidence band). ${ }^{26}$ As the figure shows, this euro area $r^{*}$ derived from our national ones compares well with alternative estimates from other studies. Unsurprisingly, the average of our national natural rates is close to the two measures of the area $r^{*}$, denoted MR and BRRWC on the figure, that are based on the model of Mésonnier and Renne (2007), which is formally very close to ours. $^{27}$ Note however that Bouis, Rawdanowicz, Renne, Watanabe and Christensen (2013) estimate their euro area $r^{*}$ conditional on their estimated potential output being very close to the level of potential output estimated by the OECD using a production function approach. Last, Holston, Laubach and Williams (2016), which implement a variant of the semi-structural model of Laubach and Williams (2003),

\footnotetext{
${ }^{26}$ We compute for each calendar year nominal GDP weights of each of the 4 countries with respect to the nominal GDP of EMU4 as a whole and use these annual weights to aggregate the national series into an "EMU4" $r$ *

${ }^{27}$ Note that Mésonnier and Renne (2007) estimate their model using quarterly series over 19792005 and define inflation as headline HICP inflation, while Bouis, Rawdanowicz, Renne, Watanabe and Christensen (2013) also estimate their model on more than three decades and look at inflation in terms of the GDP deflator.
} 
also obtain an estimated $r^{*}$ for the euro area that follows a downward trend over the years since 1999 and reaches roughly $0 \%$ in $2016 .^{28}$

As far as output gap measures are concerned, they also compare well with estimates from other sources. For instance, measures of the output gaps available at the date of this writing from the OECD, the IMF and the European Commission for the year 2016 ranged between $-0.6 \%$ and $+0.4 \%$ for Germany, between $-2.0 \%$ and $-1.5 \%$ for France, $-2.5 \%$ and $-1.6 \%$ for Italy and $-2.8 \%$ and $-1.5 \%$ in Spain. Although these values may differ to some extent from our point estimates at sample end, ours being more optimistic for core economies and less for Southern ones, they remain consistent with our estimated $95 \%$ confidence intervals around these estimates. $^{29}$ Interestingly, we also find that annual changes in our estimated output gaps strongly co-move with the respective national ESI indicators computed by Eurostat, although one should remember that the ESIs are not used for estimation. ${ }^{30}$

We also conducted a series of robustness checks of our main findings to changes in some important specifications and calibrations. First, we looked at the impact of changes in the calibration of the "risk aversion" parameters $\theta_{j}$, which largely determine the magnitude of fluctuations of the natural rate estimates, as suggested by Mésonnier and Renne (2007). ${ }^{31}$ We considered three different calibrations of the $\theta_{j}$ parameters: 3 , the baseline (between 3.5 and 3.9 depending on the country) and 5. The key estimated parameters are relatively robust to these changes. Unsurprisingly then, these alternative calibrations have little bearing on our main conclusions regarding the national interest rates and rate gaps. Second, we changed the assumption regarding the lags in the transmission of real interest rate gaps to activity. Whereas national rate gaps are assumed to impinge on the respective output gaps after two months in the baseline, we also look at the results that we obtain when this transmission takes 1 month or 3 months instead. Again, we find that our conclusions are qualitatively robust to these changes. Last, we also played with alternative calibrations for the signal-to-noise ratios, where $\sigma_{j}^{z} / \sigma_{j}^{y}=1.5$ and

\footnotetext{
${ }^{28}$ As we noted above, our replication of Holston, Laubach and Williams (2016)'s results for the euro area and the computation of the associated confidence intervals suggests that their estimate of the euro area $r^{*}$ is not statistically different from ours.

${ }^{29}$ Our upper bound is $-2.7 \%$ for Spain and $-0.9 \%$ for Italy, while our lower bounds are $-2.6 \%$ for France and $-2.2 \%$ for Germany as of June 2016 .

${ }^{30}$ See the online appendix for detailed results. The ESIs are composite confidence indicators based on surveys conducted among firms in various sectors and consumers. They are computed as averages of seasonally adjusted balances of positive and negative individual answers to questions related to, e.g., observed and expected changes in turnover, production or expenses over the last three months. As a consequence, we may expect them to be correlated with any meaningful measure of the change in the output gap, which is the difference between observed and trend output growth.

${ }^{31}$ Mésonnier and Renne (2007) find in their closely related model that the choice of this $\theta$ parameter matters much more for the qualitative results than the calibration of the signal-to-noise ratios $\left(\sigma_{j}^{z} / \sigma_{j}^{y}\right)$.
} 
2 , instead of 1 (the baseline). Our main conclusions remain qualitatively robust to changes in this ratio. ${ }^{32}$

\section{Conclusion}

To conclude, we use a parsimonious set-up to jointly estimate national time-varying natural rates of interest for the four largest economies of the euro area over 19992016. This paper is the first to estimate natural rates for individual Member countries of the euro area in a consistent framework. Our findings thus shed light on the debate on the fragmentation of the area during the euro area sovereign crisis in the first half of this decade and the relevance of a one-size-fits-all monetary policy in this stressed environment.

Indeed, we find evidence of a substantial dispersion of the gaps between real interest rates and their estimated natural counterparts across major euro-area economies during the recent euro area sovereign crisis. Accordingly, our results point to a relatively restrictive monetary policy stance in Southern economies, notably in Spain, while the policy stance remained neutral or slightly accommodative in core countries at the height of the crisis. According to our estimates, real interest rate gaps have thereafter nonetheless re-converged, to reach levels around $-1 \%$ in all four economies as of June 2016. This suggests that it took the acceleration of unconventional policies since mid-2013 to eventually achieve an accommodative policy stance in all major economies of the area and restore the conditions for an effectively common monetary policy.

We also find that diverging national interest rate gaps across economies participating in the EMU already occurred during the boom phase of the first half of the 2000s. With the benefit of hindsight, the single monetary policy stance was then clearly too accommodative in Spain, whose economic activity remained afloat because of the pre-crisis credit and housing boom, and possibly in other Southern economies as well. This clearly calls for other, national but coordinated policies to complement the single monetary policy when asymmetric shocks drive national natural interest rates apart. Macro-prudential policies and structural reforms, which should help in better matching the supply of savings and productive investment needs, are obvious candidates.

\footnotetext{
${ }^{32}$ In the interest of space, detailed tables of results and figures corresponding to all these robustness checks are left for the online appendix.
} 


\section{References}

Arrondel L, Savignac F. 2015. Risk management, housing and stockholding. Applied Economics 47: 4208-4227.

Barsky R, Justiniano A, Melosi L. 2014. The natural rate of interest and its usefulness for monetary policy. American Economic Review 104: 37-43.

Benigno P, Eggertsson G, Romei F. 2014. Dynamic debt deleveraging and optimal monetary policy. NBER Working Papers 20556, National Bureau of Economic Research, Inc.

Beyer R, Wieland V. 2017. Instability, imprecision and inconsistent use of equilibrium real interest rate estimates. IMFS Working Paper Series 110, Goethe University Frankfurt, Institute for Monetary and Financial Stability (IMFS).

Borgy V, Laubach T, Mésonnier JS, Renne JP. 2011. Fiscal sustainability, default risk and euro area sovereign bond spreads markets. Working papers 350, Banque de France.

Bouis R, Rawdanowicz L, Renne JP, Watanabe S, Christensen AK. 2013. The effectiveness of monetary policy since the onset of the financial crisis. OECD Economics Department Working Papers 1081, OECD Publishing.

Del Negro M, Giannone D, Giannoni M, Tambalotti A. 2017. Safety, liquidity, and the natural rate of interest. Staff Reports 812, Federal Reserve Bank of New York.

Eggertsson G, Ferrero A, Raffo A. 2014. Can structural reforms help europe? Journal of Monetary Economics 61: 2-22.

Eggertsson G, Mehrotra NR. 2014. A model of secular stagnation. NBER Working Papers 20574, National Bureau of Economic Research, Inc.

Friend I, Blume ME. 1975. The demand for risky assets. American Economic Review 65: 900-922.

Gali J. 2008. Introduction to Monetary Policy, Inflation, and the Business Cycle: An Introduction to the New Keynesian Framework. Princeton University Press.

Haavio M, Juillard M, Matheron J. 2016. The real natural rate in the euro area: A dsge perspective. mimeo November, Banque de France.

Hamilton J. 1986. A standard error for the estimated state vector of a state-space model. Journal of Econometrics 33: 387-397.

Hamilton J, Harris ES, Hatzius J, West K. 2015. The equilibrium real funds rate: Past, present and future. NBER Working Papers 21476, National Bureau of Economic Research, Inc.

Harvey A, Pierse R. 1984. estimating missing observations in economic time series. Journal of the American Statistical Association 79: 1-36.

Holston K, Laubach T, Williams J. 2016. Measuring the natural rate of interest: International trends and determinants. Working Paper Series 2016-11, Federal Reserve Bank of San Francisco. 
Kocherlakota N. 2015. Fiscal policy and the long-run neutral real interest rate. Speech at the Bundesbank Conference, Frankfurt, Germany, July 9, 2015 135, Federal Reserve Bank of Minneapolis.

Laubach T, Williams J. 2003. Measuring the natural rate of interest. The Review of Economics and Statistics 85: 1063-1070.

Laubach T, Williams J. 2015. Measuring the natural rate of interest redux. Working Paper Series 2015-16, Federal Reserve Bank of San Francisco.

Lewis KF, Vazquez-Grande F. 2017. Measuring the Natural Rate of Interest: Alternative Specifications. Finance and Economics Discussion Series 2017-059, Board of Governors of the Federal Reserve System (U.S.).

Mavroeidis S, Plagborg-Moller M, Stock JH. 2014. Empirical evidence on inflation expectations in the new keynesian phillips curve. Journal of Economics Literature 52: $124-188$.

Mésonnier JS, Renne JP. 2007. A time-varying "natural" rate of interest for the euro area. European Economic Review 51: 1768-1784.

Pesaran MH, Schuermann T, Weiner SM. 2004. Modeling regional interdependencies using a global error-correcting macroeconometric model. Journal of Business 83 Economic Statistics 22: 129-162.

Pesenti P. 2015. Strutural reforms and monetary policy revisited. In Low for Long? Causes and Consequences of Persistently Low Interest Rates. Centre for Economic Policy Research, 152-161.

Rachel L, Smith T. 2015. Secular drivers of the global real interest rate. Bank of England working papers 571, Bank of England.

Rudd J, Whelan K. 2007. Modeling inflation dynamics: A critical review of recent research. Journal of Money, Credit and Banking 39: 155-170.

Rudebusch G, Svensson L. 1999. Policy rules for inflation targeting. In Monetary Policy Rules. National Bureau of Economic Research, Inc, 203-262.

Wicksell K. 1898[1936]. Interest and Prices. London: Macmillan.

Woodford M. 2003. Interest and Prices: Foundations of a Theory of Monetary Policy. Princeton University Press. 
Table 1: Calibrated parameters

\begin{tabular}{cccccc}
\hline \hline & $\theta_{r}$ & $\mu^{r}$ & $\mu^{y}$ & $\sigma^{z} / \sigma^{y}$ & $\sigma^{a}$ \\
\hline Spain & 3.7 & 0.30 & 1.80 & 1 & 0.05 \\
Italy & 3.9 & 0.63 & 0.28 & 1 & 0.07 \\
France & 3.5 & 0.53 & 1.35 & 1 & 0.08 \\
Germany & 3.7 & 0.43 & 1.31 & 1 & 0.09 \\
\hline \hline
\end{tabular}

Table 2: Intra-euro area trade weights

\begin{tabular}{lcccc}
\hline \hline & SP & IT & FR & DE \\
\hline SP & 0.0 & 2.2 & 4.7 & 2.9 \\
IT & 1.9 & 0.0 & 3.6 & 4.2 \\
FR & 2.4 & 2.4 & 0.0 & 4.5 \\
DE & 2.1 & 3.3 & 5.2 & 0.0 \\
\hline \hline
\end{tabular}

This matrix collects the $\chi_{j k}$ parameters in the IS curve equations of each country $j$ and reads as follows: exports of country $j$ (in lines) towards country $k$ (in columns) as a ratio of the GDP of country $j(\%)$.

Table 3: Parameter estimates I

\begin{tabular}{ccc|cc|cc|cc}
\hline \hline & \multicolumn{2}{c}{ Spain } & \multicolumn{2}{c}{ Italy } & \multicolumn{2}{c}{ France } & \multicolumn{2}{c}{ Germany } \\
\hline Parameter & value & t-student & value & t-student & value & t-student & value & t-student \\
\hline$\gamma$ & 0.39 & 5.83 & -0.07 & -1.03 & -0.00 & -0.04 & -0.43 & -6.68 \\
$\beta$ & 0.08 & 3.21 & 0.20 & 3.87 & 0.36 & 2.50 & 0.26 & 2.05 \\
$\sigma_{\pi}$ & 1.58 & 20.15 & 1.31 & 19.99 & 1.38 & 19.98 & 1.70 & 19.23 \\
$\alpha$ & 0.98 & 152.18 & 1.01 & 47.05 & 0.96 & 17.99 & 0.97 & 44.46 \\
$\delta$ & 0.75 & 3.76 & 0.10 & 0.31 & 0.38 & 1.28 & 0.51 & 2.66 \\
$\lambda$ & -0.14 & -9.16 & -0.13 & -6.67 & -0.10 & -4.56 & -0.13 & -4.34 \\
$\psi$ & 0.95 & 69.80 & 0.92 & 39.92 & 0.94 & 50.35 & 0.91 & 28.91 \\
$\varphi_{\text {IPI }}$ & 1.66 & 4.38 & 2.87 & 9.18 & 3.05 & 5.41 & 2.13 & 7.34 \\
$\mu_{\text {IPI }}$ & -3.76 & -2.96 & -1.93 & -2.13 & -4.61 & -3.51 & -1.16 & -1.08 \\
$\sigma_{\text {IPI }}$ & 15.35 & 19.54 & 12.96 & 14.46 & 15.34 & 16.49 & 14.40 & 15.69 \\
$\sigma_{y}$ & 1.25 & 8.18 & 1.68 & 9.38 & 1.18 & 9.00 & 2.08 & 9.39 \\
\hline \hline
\end{tabular}

Model parameters are estimated by maximizing the likelihood function computed with the Kalman filter. Standard deviations are estimated using the Hessian matrix of the log-likelihood function. 
Table 4: Parameter estimates II: correlation matrix of $r^{*}$ shocks $(\Sigma)$

\begin{tabular}{c|cccc|cccc}
\hline \hline & \multicolumn{5}{|c}{$\widehat{\Sigma}$} \\
\hline & SP & IT & FR & DE & SP & IT & FR & DE \\
SP & 1 & 0.883 & 0.930 & 0.716 & & 10.04 & 12.67 & 4.39 \\
IT & $\cdot$ & 1 & 0.963 & 0.929 &. & & 31.87 & 14.44 \\
FR & $\cdot$ & $\cdot$ & 1 & 0.877 &. &. & & 7.98 \\
DE & $\cdot$ & $\cdot$ & $\cdot$ & 1 &. &. &. & \\
\hline \hline
\end{tabular}

Model parameters are estimated by maximizing the likelihood function computed with the Kalman filter. Standard deviations are estimated using the Hessian matrix of the log-likelihood function. 
Figure 1: Smoothed trajectories of the national natural interest rates.
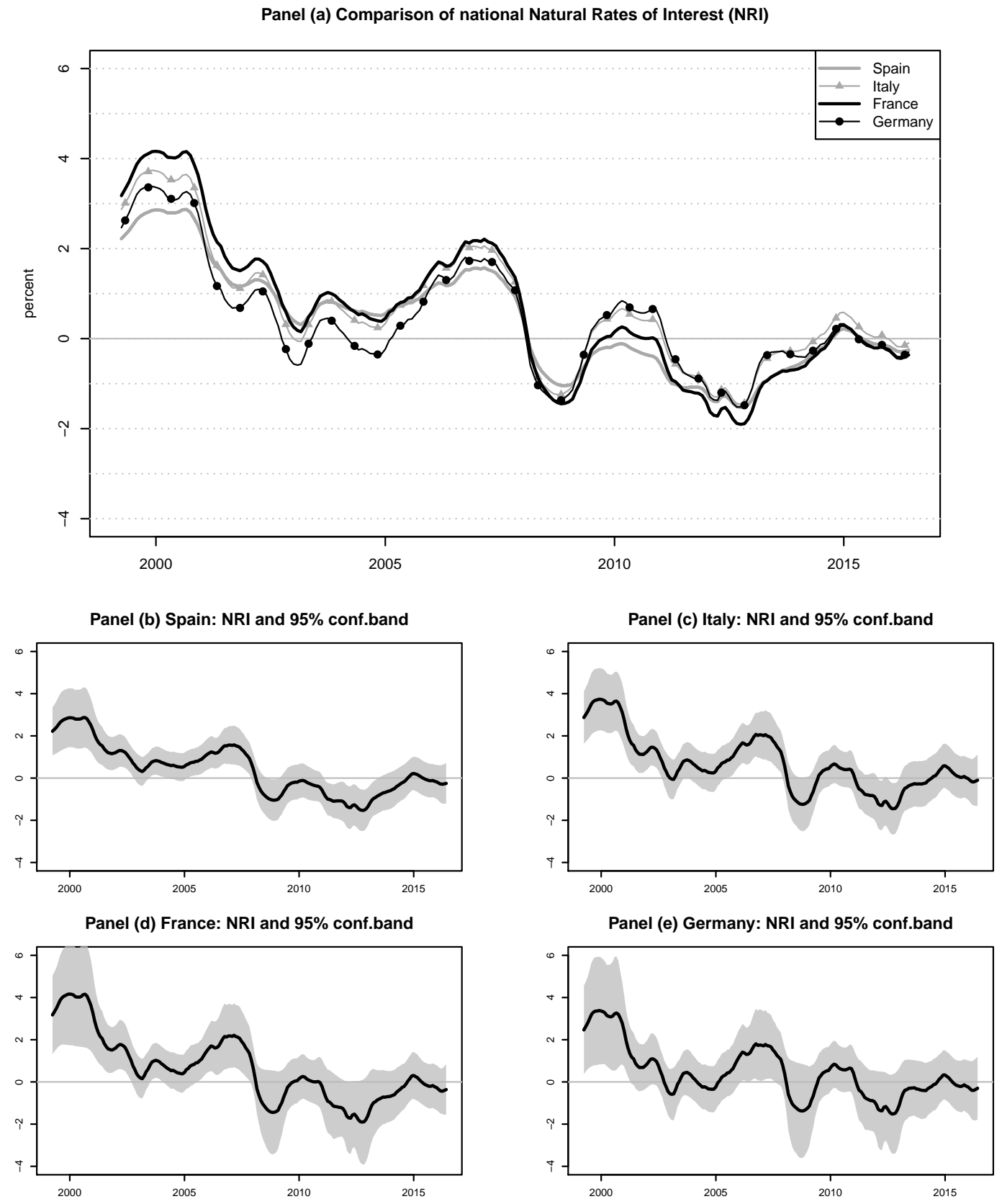
Figure 2: Smoothed trajectories of the national interest rate gaps with 95\% confidence intervals.
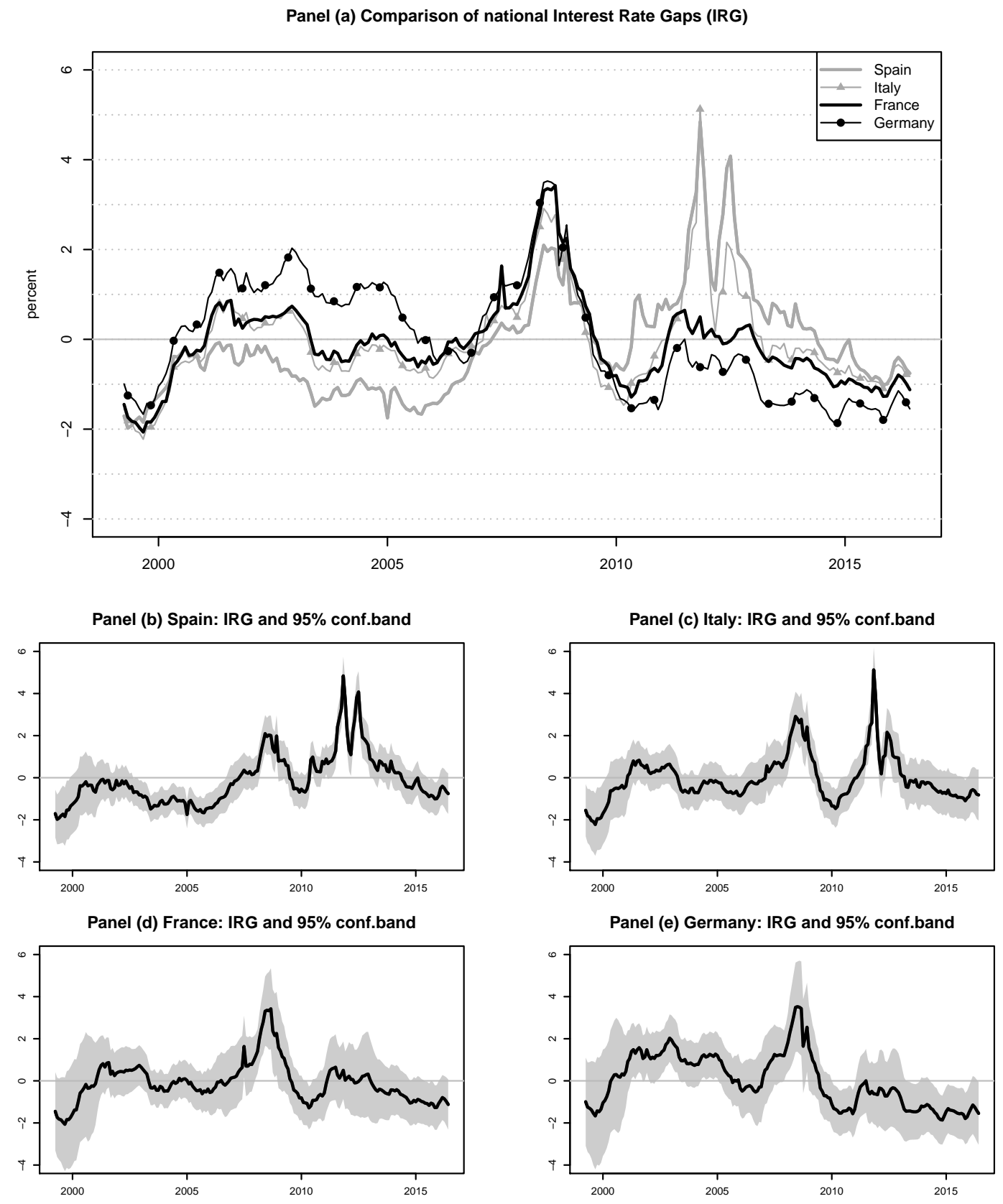
Figure 3: Smoothed trajectories of the national output gaps with $95 \%$ confidence intervals.
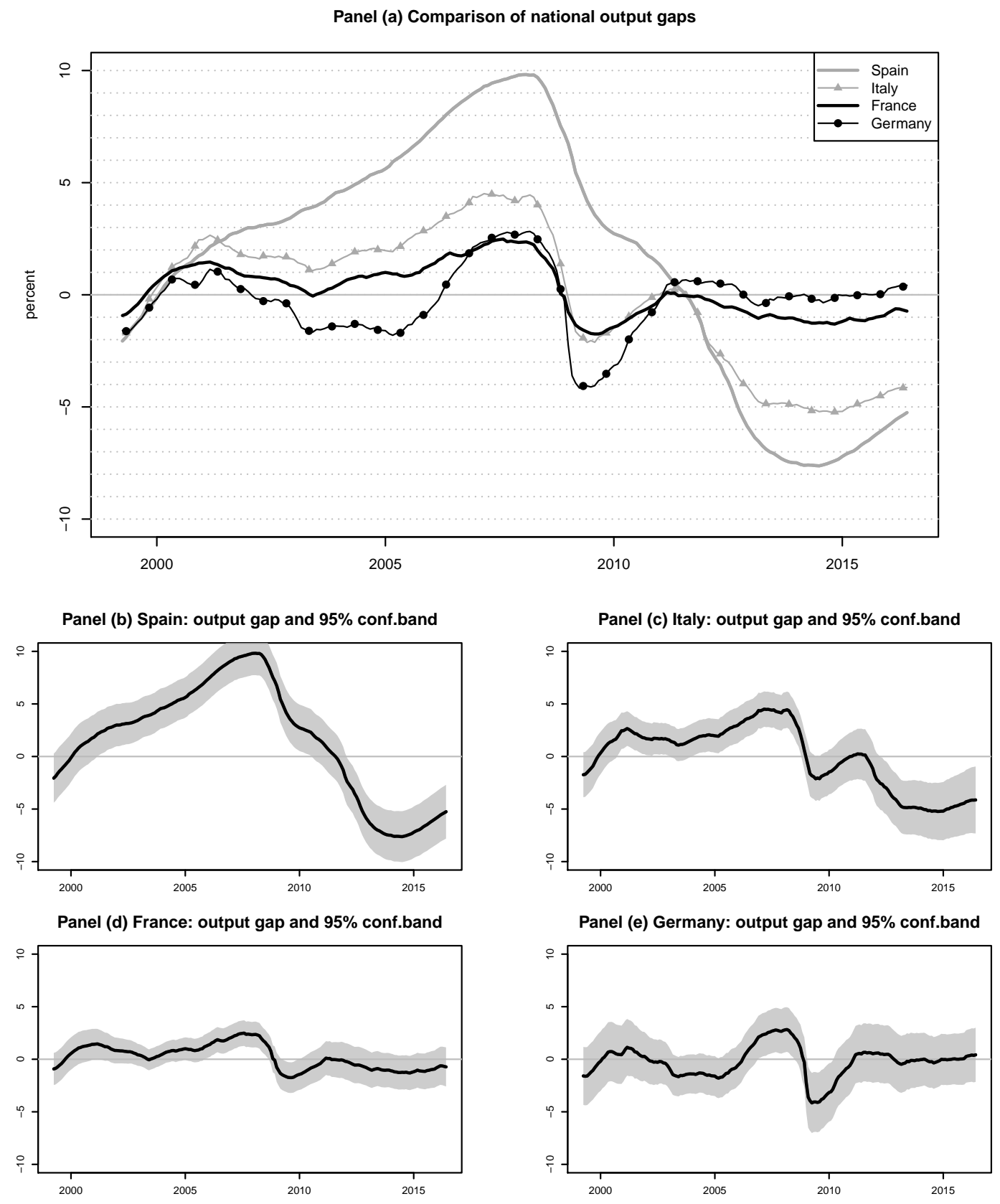
Figure 4: Bilateral spreads of national natural interest rates and interest rate gaps with $95 \%$ confidence intervals.
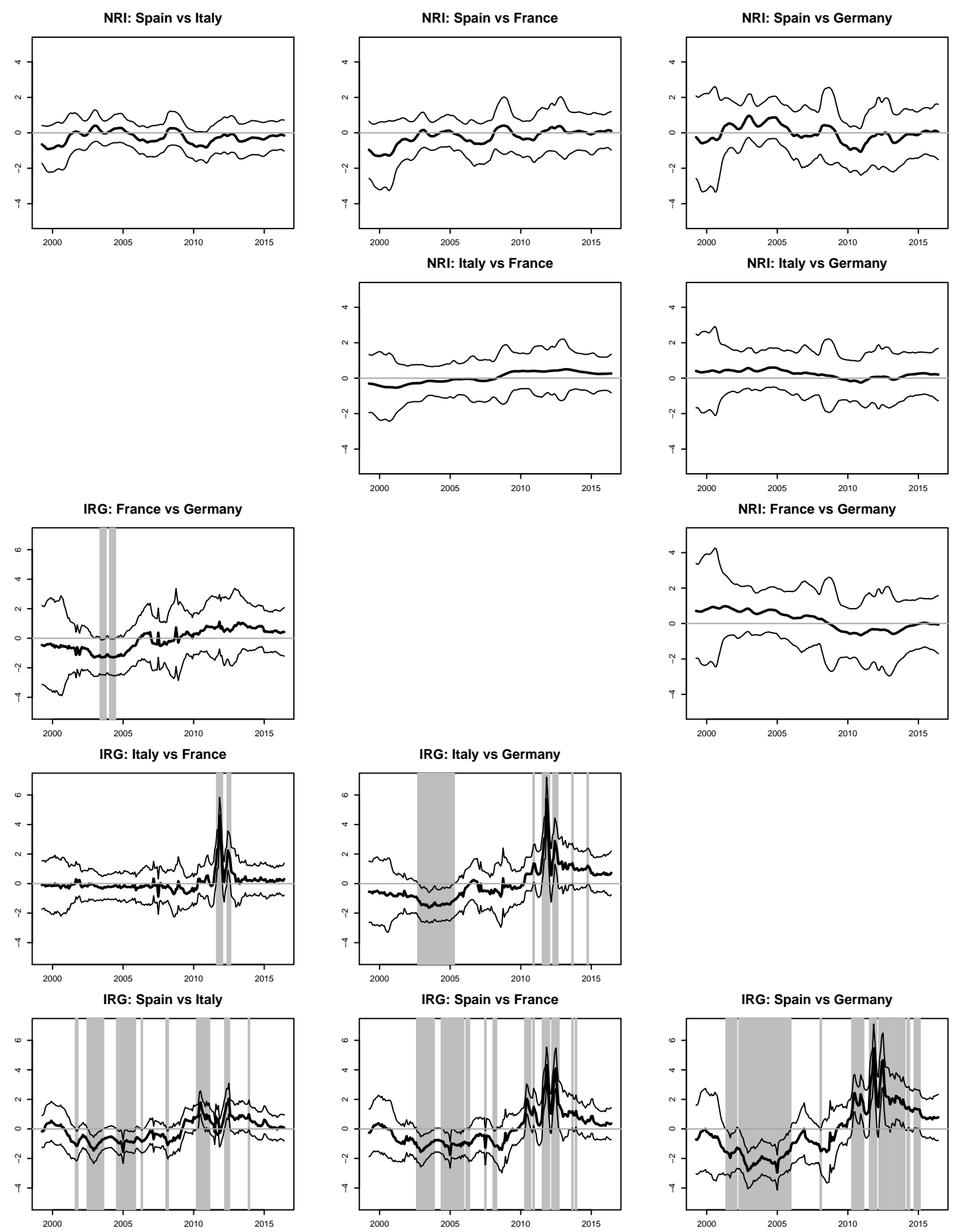

The shaded areas indicate periods where the spreads are statistically significant at the $95 \%$ level. 
Figure 5: Alternative estimates of the euro area natural rate of interest.

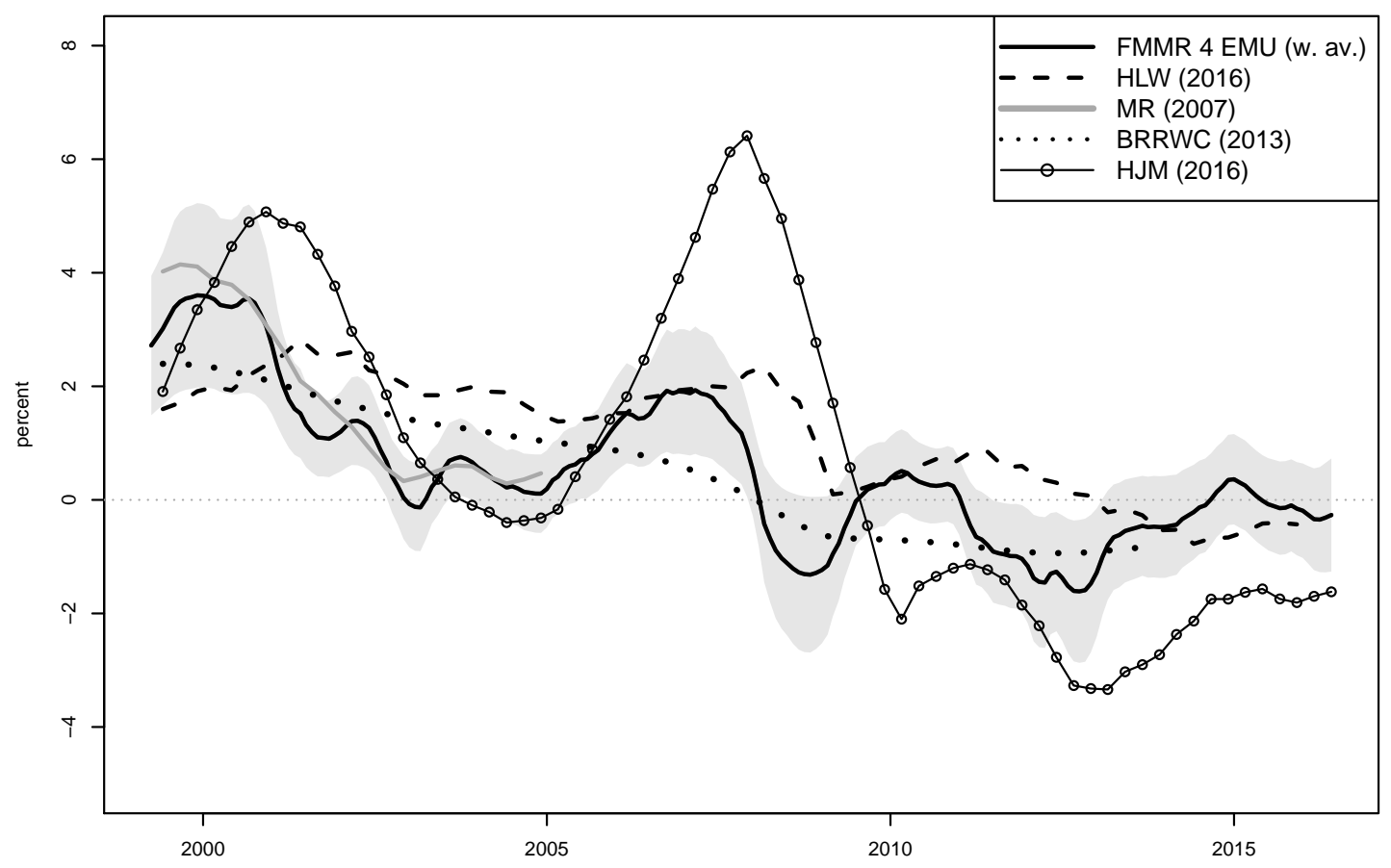

FMMR 4 EMU is the average of the national $r^{*}$ estimated for the largest for countries in this paper, weighted by the share of each country in the nominal GDP of EMU4. HLW 2016 is the euro area $r^{*}$ estimated by Holston, Laubach and Williams (2016). MR 2007 is the baseline euro area $r^{*}$ as estimated in Mésonnier and Renne (2007). BRRWC 2013 refers to the baseline euro area $r^{*}$ estimated in Bouis, Rawdanowicz, Renne, Watanabe and Christensen (2013). Last, HJM 2016 is the DSGE estimate of Haavio, Juillard and Matheron (2016) 


\section{Online appendix}

[Not for publication]

\section{National natural rates of interest and the single monetary policy in the euro area.}

Sébastien Fries, Jean-Stéphane Mésonnier, Sarah Mouabbi and Jean-Paul Renne.

\section{A State space form of the model}

\section{A.1 Dealing with quarterly GDP in a monthly model of po- tential growth}

Let us denote by $y_{j t}$ the (unobserved) monthly $\log$ GDP of country $j$. We can write:

$$
\begin{aligned}
& \Delta y_{j t}=\Delta y_{j t}^{*}+\Delta z_{j t} \\
& \Delta y_{j t}=\mu_{j}^{y}+a_{j t}+z_{j t}-z_{j, t-1}+\epsilon_{j t}^{y} .
\end{aligned}
$$

This equation cannnot however be included among our measurement equation since monthly GDP is not observed. Let us denote by $\Delta y_{j t}^{Q}$ the observed quarterly growth rate of GDP. We define $\Delta y_{j t}$ such that:

$$
\Delta y_{j t}^{Q}=\frac{1}{3}\left(\Delta y_{j t}+\Delta y_{j, t-1}+\Delta y_{j, t-2}\right) .
$$

Hence, by substituting for $\Delta y_{j t}$, we get:

$$
\Delta y_{j t}^{Q}=\mu_{j}^{y}+\frac{1}{3}\left(a_{j t}+a_{j, t-1}+a_{j, t-2}\right)+\frac{1}{3}\left(z_{j t}-z_{j, t-3}\right)+\frac{1}{3}\left(\epsilon_{j t}^{y}+\epsilon_{j, t-1}^{y}+\epsilon_{j, t-2}^{y}\right) .
$$

The Kalman filter can be adapted so as to deal with missing observations in the measurement equations (see Harvey and Pierse, 1984). However, having less data for the same number of parameters to be estimated will mechanically lead to a higher uncertainty of parameter estimates and of the filtered trajectories of the latent variables. This is all the more a concern than our sample is relatively small: it includes about 200 monthly observations for each country, but only about 70 GDP observations.

To solve this problem, we augment the model with an additional measurement equation where we use the growth rate in the monthly Industrial Production Index (IPI) as a proxy for monthly GDP growth, $\Delta y$ :

$$
\Delta_{j t}^{\mathrm{IPI}}=\mu_{j}^{\mathrm{IPI}}+\varphi_{j} \Delta y_{j t}+\epsilon_{j t}^{\mathrm{IPI}},
$$

where $\epsilon_{j t}^{\mathrm{IPI}} \stackrel{i i d}{\sim} \mathcal{N}\left(0,\left(\sigma_{j}^{I P I}\right)^{2}\right)$ and $\mu_{j}^{\mathrm{IPI}}, \varphi_{j}$ and $\sigma_{j}^{I P I}>0$ are constants to be estimated. Substituting $\Delta y_{j t}$ by its expression from (3), we get:

$$
\Delta_{j t}^{\mathrm{IPI}}=\varphi_{j} \mu_{j}^{y}+\mu_{j}^{\mathrm{IPI}}+\varphi_{j}\left(a_{j t}+z_{j t}-z_{j, t-1}+\epsilon_{j t}^{y}\right)+\epsilon_{j t}^{\mathrm{IPI}} .
$$




\section{A.2 State-space form of the model}

For any country $j$, let $s_{j}, p_{j}$ and $q_{j}$ be the number of lags to be included in the system respectively for the inflation in the $\mathrm{PC}$ (with parameters $\left(\gamma_{j 1}, \ldots, \gamma_{j s_{j}}\right)$ ), the autoregressive component of the output gap in the IS equation(with parameters $\left.\left(\alpha_{j 1}, \ldots, \alpha_{j p_{j}}\right)\right)$ ) and the output gaps in the $\mathrm{PC}$ (with parameters $\left(\beta_{j 1}, \ldots, \beta_{j q_{j}}\right)$ ). Let $l_{j}$ be the single lag order of the interest rate gap to be included in the IS equation. In practice, we use the same number and order of lags for all countries.

- Measurement equations

$$
\left\{\begin{aligned}
\Delta y_{j t}^{Q} & =\mu_{j}^{y}+\frac{1}{3}\left(a_{j t}+a_{j, t-1}+a_{j, t-2}\right)+\frac{1}{3}\left(z_{j t}-z_{j, t-3}\right)+\frac{1}{3}\left(\epsilon_{j t}^{y}+\epsilon_{j, t-1}^{y}+\epsilon_{j, t-2}^{y}\right) \\
\pi_{j t} & =\mu_{j}^{\pi}+\sum_{l=1}^{s_{j}} \gamma_{j l} \pi_{j, t-l}+\sum_{l=1}^{q_{j}} \beta_{j l} z_{j, t-l}+\epsilon_{j t}^{\pi} \\
\Delta_{j t}^{\mathrm{IPI}} & =\varphi_{j} \mu_{j}^{y}+\mu_{j}^{\mathrm{IPI}}+\varphi_{j}\left(a_{j t}+z_{j t}-z_{j, t-1}+\epsilon_{j t}^{y}\right)+\epsilon_{j t}^{\mathrm{IPI}}
\end{aligned}\right.
$$

- Transition equations (excluding identities)

$$
\left\{\begin{array}{l}
a_{j t}=\psi_{j} a_{j, t-1}+\epsilon_{j t}^{a} \\
z_{j t}=\sum_{l=1}^{p_{j}} \alpha_{j l} z_{j, t-l}+\delta_{j} \sum_{k=1}^{n} \chi_{j k} z_{k, t-1}+\lambda_{j}\left(i_{j, t-l_{j}}-\mathbb{E}_{t-l_{j}}\left[\pi_{j, t-l_{j}, t-l_{j}+h}\right]\right)-\lambda_{j} \theta_{j} a_{j, t-l_{j}}-\lambda_{j} \mu_{j}^{r}+\epsilon_{j t}^{z}
\end{array}\right.
$$

where $\bar{p}_{j}=\max \left(p_{j}, q_{j}\right)$.

$\epsilon_{1 t}^{\pi}, \ldots, \epsilon_{n t}^{\pi}, \epsilon_{1 t}^{y}, \ldots, \epsilon_{n t}^{y}, \epsilon_{1 t}^{z}, \ldots, \epsilon_{n t}^{z}$ are all assumed to be pairwise independent. Moreover, note that $\epsilon_{1 t}^{a}, \ldots, \epsilon_{n t}^{a}$ are correlated and we denote by $\Sigma$ the corresponding variancecovariance matrix of the Gaussian vector $\left(\epsilon_{1 t}^{a}, \ldots, \epsilon_{n t}^{a}\right)$ and $\left(\rho_{j k}\right)$ the correlation coefficients.

We assume that expected inflation at the future date $t+h$ conditional on the information available at $t$ is measured without error by the Consensus Economics forecast. Formally, this implies:

$$
\mathbb{E}_{t}\left[\pi_{j, t, t+h}\right]=\pi_{j, t, t+h}^{c}
$$

For each country $j$, the system can be written under the following matrix formulation:

$$
\left\{\begin{array}{l}
Y_{j t}=A_{j} Z_{j t}+B_{j} X_{j t}^{1}+m_{j}^{1}+\epsilon_{j t}^{Y} \\
Z_{j t}=C_{j} Z_{j, t-1}+D_{j} X_{j t}^{2}+m_{j}^{2}+\epsilon_{j t}^{Z}
\end{array}\right.
$$

where $Y_{j t}$ is the vector of observed variables and $Z_{j t}$ is the vector of state variables:

$$
Y_{j t}=\left(\begin{array}{c}
\Delta y_{j t}^{Q} \\
\pi_{j t} \\
\Delta_{j t}^{\mathrm{IPI}}
\end{array}\right) \quad Z_{j t}=\left(\begin{array}{c}
a_{j t} \\
a_{j, t-1} \\
a_{j, t-2} \\
\epsilon_{j t}^{y} \\
\epsilon_{j, t-1}^{y} \\
\epsilon_{j, t-2}^{y} \\
z_{j t} \\
\vdots \\
z_{j, t-\bar{p}_{j}}
\end{array}\right) .
$$


$X_{j t}^{1}$ and $X_{j t}^{2}$ are vectors containing the exogenous and predetermined variables:

$$
X_{j t}^{1}=\left(\begin{array}{c}
\pi_{j, t-1} \\
\vdots \\
\pi_{j, t-\bar{p}_{j}}
\end{array}\right) \quad X_{j t}^{2}=\left(\begin{array}{c}
i_{j, t-l_{j}} \\
\pi_{j, t-l_{j} \mid t-l_{j}+h}^{c}
\end{array}\right)
$$

$m_{j}^{1}$ and $m_{j}^{2}$ are drift terms:

$$
m_{j}^{1}=\left(\begin{array}{c}
\mu_{j}^{y} \\
\mu_{j}^{\pi} \\
\varphi_{j}^{\mathrm{IPI}} \mu_{j}^{y}+\mu_{j}^{\mathrm{IPI}}
\end{array}\right) \quad m_{j}^{2}=\left(\begin{array}{c}
\mathbf{0}_{\mathbb{R}^{6}} \\
-\lambda_{j} \mu_{j}^{r} \\
\mathbf{0}_{\mathbb{R}^{\bar{p}_{j}}}
\end{array}\right)
$$

$\epsilon_{j t}^{Y}$ and $\epsilon_{j t}^{Z}$ are independent multivariate Gaussian white noises:

$$
\epsilon_{j t}^{Y}=\left(\begin{array}{c}
0 \\
\epsilon_{j t}^{\pi} \\
\epsilon_{j t}^{\mathrm{ESI}}
\end{array}\right) \quad \epsilon_{j t}^{Z}=\left(\begin{array}{c}
\epsilon_{j t}^{a} \\
0 \\
0 \\
\epsilon_{j t}^{y} \\
0 \\
0 \\
\epsilon_{j t}^{z} \\
\mathbf{0}_{\mathbb{R}^{\bar{p}} j}
\end{array}\right) .
$$

Finally, the remaining matrices $A_{j}, B_{j}, C_{j}$ and $D_{j}$ are coefficients matrices which could be time-varying in the general case, but here are considered constant:

$$
\begin{aligned}
& A_{j}=\left(\begin{array}{ccccccccccccc}
\frac{1}{3} & \frac{1}{3} & \frac{1}{3} & \frac{1}{3} & \frac{1}{3} & \frac{1}{3} & \frac{1}{3} & 0 & 0 & -\frac{1}{3} & 0 & \cdots & 0 \\
0 & 0 & 0 & 0 & 0 & 0 & 0 & \beta_{j 1} & & \cdots & \cdots & & \beta_{j \bar{p}_{j}} \\
\varphi_{j} & 0 & 0 & \varphi_{j} & 0 & 0 & \varphi_{j} & -\varphi_{j} & 0 & 0 & 0 & 0 & 0
\end{array}\right) \\
& B_{j}=\left(\begin{array}{ccc}
0 & \cdots & 0 \\
\gamma_{j 1} & \cdots & \gamma_{j \bar{p}_{j}} \\
0 & \cdots & 0
\end{array}\right) \\
& C_{j}=\left(\begin{array}{cccccccccc}
\psi_{j} & 0 & 0 & 0 & 0 & 0 & 0 & 0 & 0 & 0 \\
1 & 0 & 0 & 0 & 0 & 0 & 0 & 0 & 0 & 0 \\
0 & 1 & 0 & 0 & 0 & 0 & 0 & 0 & 0 & 0 \\
0 & 0 & 0 & 0 & 0 & 0 & 0 & 0 & 0 & 0 \\
0 & 0 & 0 & 1 & 0 & 0 & 0 & 0 & 0 & 0 \\
0 & 0 & 0 & 0 & 1 & 0 & 0 & 0 & 0 & 0 \\
-\lambda_{j} \theta_{j} \mathbb{1}_{l_{j}=1} & -\lambda_{j} \theta_{j} \mathbb{1}_{l_{j}=2} & -\lambda_{j} \theta_{j} \mathbb{1}_{l_{j}=3} & 0 & 0 & 0 & \alpha_{j 1} & \cdots & \alpha_{j \bar{p}_{j}} & 0 \\
0 & 0 & 0 & 0 & 0 & 0 & 1 & \mathbf{0} & \mathbf{0} & 0 \\
\vdots & \vdots & \vdots & \vdots & \vdots & \vdots & \mathbf{0} & \ddots & \mathbf{0} & \vdots \\
0 & 0 & 0 & 0 & 0 & 0 & \mathbf{0} & \mathbf{0} & 1 & 0
\end{array}\right)
\end{aligned}
$$

where $\mathbb{1}_{l_{j}=c}=1$ if $l_{j}=c$ and 0 otherwise. 


$$
D_{j}=\left(\begin{array}{cc}
0 & 0 \\
0 & 0 \\
0 & 0 \\
0 & 0 \\
0 & 0 \\
0 & 0 \\
\lambda_{j} & -\lambda_{j} \\
0 & 0 \\
\vdots & \vdots \\
0 & 0
\end{array}\right)
$$

where $C_{j}$ and $D_{j}$ have the same number of rows as the state vector $Z_{j t}$, that is $7+\bar{p}_{j}$.

Omitting for a moment the term $\delta_{j} \sum_{k=1}^{n} \chi_{j k} z_{k, t-1}$, the complete system including all the countries of interest also admits a compact matrix formulation. We define the new vectors standing for the observed and the state variables by stacking the $\left(Y_{j t}\right)_{j \in \llbracket 1, n \rrbracket}$ and $\left(Z_{j t}\right)_{j \in \llbracket 1, n \rrbracket}$ :

$$
Y_{t}=\left(\begin{array}{c}
Y_{1 t} \\
\vdots \\
Y_{n t}
\end{array}\right) \quad Z_{t}=\left(\begin{array}{c}
Z_{1 t} \\
\vdots \\
Z_{n t}
\end{array}\right)
$$

$m^{1}, m^{2}, \epsilon_{t}^{Y}$ and $\epsilon_{t}^{Z}$ are defined similarly. Finally, for the remaining matrices $\left(A_{j}\right)_{j \in \llbracket 1, n \rrbracket}$, $\left(B_{j}\right)_{j \in \llbracket 1, n \rrbracket},\left(C_{j}\right)_{j \in \llbracket 1, n \rrbracket}$ and $\left(D_{j}\right)_{j \in \llbracket 1, n \rrbracket}$, we use the notation:

$$
M=\left(\begin{array}{ccc}
M_{1} & & \mathbf{0} \\
& \ddots & \\
\mathbf{0} & & M_{n}
\end{array}\right)
$$

Hence, the complete system can now be written as:

$$
\left\{\begin{array}{l}
Y_{t}=A Z_{t}+B X_{t}^{1}+m^{1}+\epsilon_{t}^{Y} \\
Z_{t}=C Z_{t-1}+D X_{t}^{2}+m^{2}+\epsilon_{t}^{Z}
\end{array}\right.
$$

In order to introduce the term that we previously omitted, the matrix formulation of the system is slightly adapted. We denote $J_{Z}$ the square matrix of same size as the dimension of the state vector, $Z_{t}$, full of zeros except the $7^{\text {th }}$ diagonal term (the one corresponding to the position of $z_{t}$ in the state vector) equal to 1 , and $\delta=\operatorname{diag}\left(\delta_{1}, \ldots, \delta_{n}\right)$ is a hyper-parameter that needs to be estimated. It can be shown that the system now reads: 


$$
\left\{\begin{array}{l}
Y_{t}=A Z_{t}+B X_{t}^{1}+m^{1}+\epsilon_{t}^{Y} \\
Z_{t}=C Z_{t-1}+D X_{t}^{2}+m^{2}+\epsilon_{t}^{Z}+\left(\left(\delta \chi_{t}\right) \otimes J_{Z}\right) Z_{t-1}
\end{array}\right.
$$

Hence:

$$
\left\{\begin{array}{l}
Y_{t}=\quad A Z_{t}+B X_{t}^{1}+m^{1}+\epsilon_{t}^{Y} \\
Z_{t}=\left(C+(\delta \chi) \otimes J_{Z}\right) Z_{t-1}+D X_{t}^{2}+m^{2}+\epsilon_{t}^{Z}
\end{array}\right.
$$

\section{B Initialization of the filtering and optimization al- gorithms}

\section{B.1 Initialization of the optimization algorithm}

The model is heavily parameterized, so that maximum likelihood estimates of the free parameters may correspond to local optima of the likelihood function. A careful choice of the initial parameter values used to kick-start the gradient descent algorithm therefore matters for the quality of the results.

We proceed in two steps. ${ }^{33}$ First, we estimate a simplified model for each of the four countries where we shut down the trade channel in the IS equation and assume a diagonal correlation matrix $\Sigma$ for productivity shocks. For each country, we initialize our parameter estimates with the baseline values of the corresponding euro area parameters estimated in Mésonnier and Renne (2007). After this first step, we thus get four different sets of parameters, one for each country, and we also get filtered and smoothed trajectories of the latent variables. ${ }^{34}$ In a second step, we estimate the full model by opening up the two international contagion channels. Parameter estimates obtained for each country separately in the first step are then used as initial values for the second one. There are however additional parameters to initialize, namely the $\delta_{j}$ and the non-diagonal elements in the correlation matrix $\Sigma$. For this purpose, we use outputs of the first step: the smoothed trajectories of the national output gaps and of the national productivity processes. We run OLS regressions of the IS equations with estimated output gap series to get an initial value for $\delta_{j}$ and use the empirical correlation matrix of the productivity shocks from the first step as an initial value for $\Sigma$.

\section{B.2 Initialization of the optimization algorithm}

For a given set of parameters, the optimization algorithm runs the Kalman filter and computes the likelihood function, to be maximized upon. Using the Kalman filter however requires to choose the initial first and second order moments -including all covariances- of the state vector, which stacks all unobservable variables. We detail in this section how we proceed with this initialization.

Recall that for each country $j$, this state vector can be divided in three blocks:

\footnotetext{
${ }^{33}$ Note however that, once the algorithm has been initialized in a sensible way as described below, the estimation of all parameters and unobservable variables is carried out in one unique step.

${ }^{34}$ The Kalman algorithm provides two types of estimates of the latent factors. The first are filtered estimates, which correspond to the expectations of the latent variables conditional on past and present observations. The second are smoothed estimates, which correspond to the expectations of the latent variables conditional on all observations (past, present and future).
} 


$$
\left(\begin{array}{c}
a_{j t} \\
a_{j, t-1} \\
a_{j, t-2}
\end{array}\right) \quad\left(\begin{array}{c}
\epsilon_{j t} \\
\epsilon_{j, t-1} \\
\epsilon_{j, t-2}
\end{array}\right) \quad\left(\begin{array}{c}
z_{j t} \\
\vdots \\
z_{j, t-\bar{p}_{j}}
\end{array}\right)
$$

Moments of $\left(\mathbf{a}_{\mathbf{j t}}\right)$ Since the dynamic of the productivity process is assumed to be an $\operatorname{AR}(1)$, we can analytically derive the unconditional moments, which are the natural candidates for the initial point.

Moments of $\left(\epsilon_{\mathbf{j} \mathbf{t}}^{\mathbf{y}}\right)$ We already know that the first order moment of the elements of this block is zero and their variances are equal to $\sigma_{j}^{y 2}$. Besides, since our specification assumes these shocks as independent from all other processes and across time, we get straightforwardly that all the covariances are nil.

Moments of $\left(\mathbf{z}_{\mathbf{j} \mathbf{t}}\right)$ Regarding the mean and autocovariance of $\left(\mathbf{z}_{\mathbf{j} \mathbf{t}}\right)$, and cross-country covariances $\operatorname{Cov}\left(z_{j t}, z_{k, t-l}\right)$, we opt for the empirical approach performed in Mésonnier and Renne (2007): we first extract proxies of the output gaps of each country by applying the Hodrick-Prescott filter on GDP data, and we then compute the sample mean and covariance using these proxies.

\section{Building confidence intervals of the estimated un- observable factors}

A useful output of the Kalman filter is the covariance matrix of the factors, which allows us to build confidence intervals around the trajectories of the filtered and smoothed state variables. As pointed out by Hamilton (1986), those confidence intervals are conditioned on the knowledge of the parameters of the model, which are in fact estimated by maximum likelihood. He provides a method to build global confidence intervals that also takes into account the uncertainty around the parameter estimates. Following Hamilton's approach, after having performed the estimation and computed the covariance matrix of the parameter estimates, we generate $M$ sets of parameters from the asymptotic distribution of our estimators:

$$
\theta_{j} \stackrel{i i d}{\sim} \mathcal{N}(\widehat{\theta}, \widehat{\mathbf{V}})
$$

where $\widehat{\theta}$ is the maximum likelihood estimate and $\widehat{V}$ is the corresponding covariance matrix computed using the Hessian of the likelihood at $\widehat{\theta}$. For each set of parameters $\theta_{j}$, we run the Kalman filter and get both the covariance matrix of the factors $\mathbf{P}_{t}^{j}$ (filtered or smoothed), and the trajectories of these factors $\mathbf{Z}_{t}^{j}$, at all dates $t$. Hamilton (1986) shows that the global variance around the factors at any date $t$ can be approximated by:

$$
\overline{\mathbf{P}}_{t}=\frac{1}{M} \sum_{j=1}^{M} \mathbf{P}_{t}^{j}+\frac{1}{M} \sum_{j=1}^{M}\left(\mathbf{Z}_{t}^{j}-\overline{\mathbf{Z}}_{t}\right) t\left(\mathbf{Z}_{t}^{j}-\overline{\mathbf{Z}}_{t}\right)
$$

where: $\overline{\mathbf{Z}}_{t}=\frac{1}{M} \sum_{j=1}^{M} \mathbf{Z}_{t}^{j}$. 


\section{Input data}

Figure D.1: Data

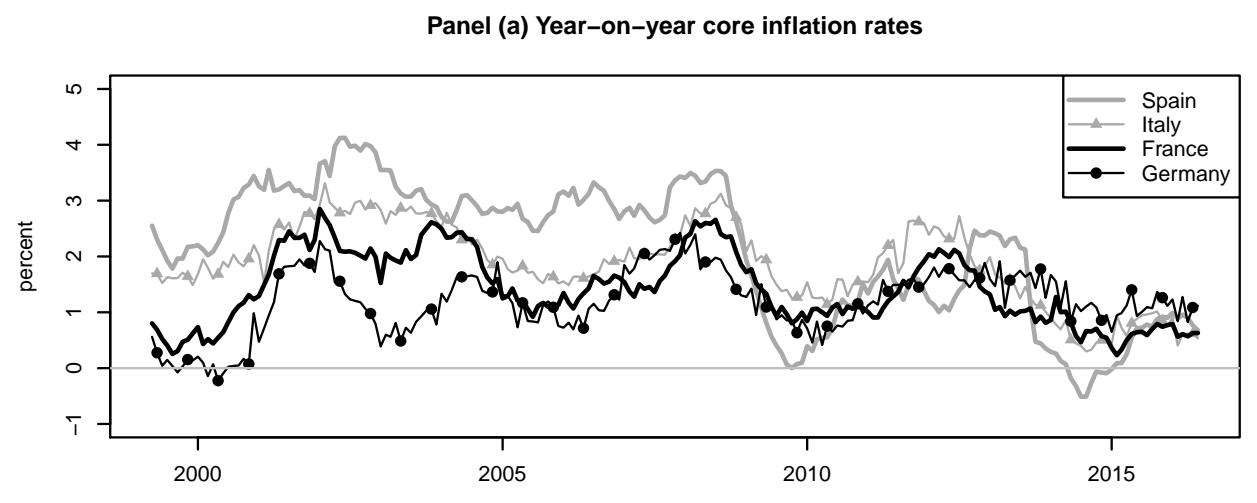

Panel (b) Quarterly GDP growth

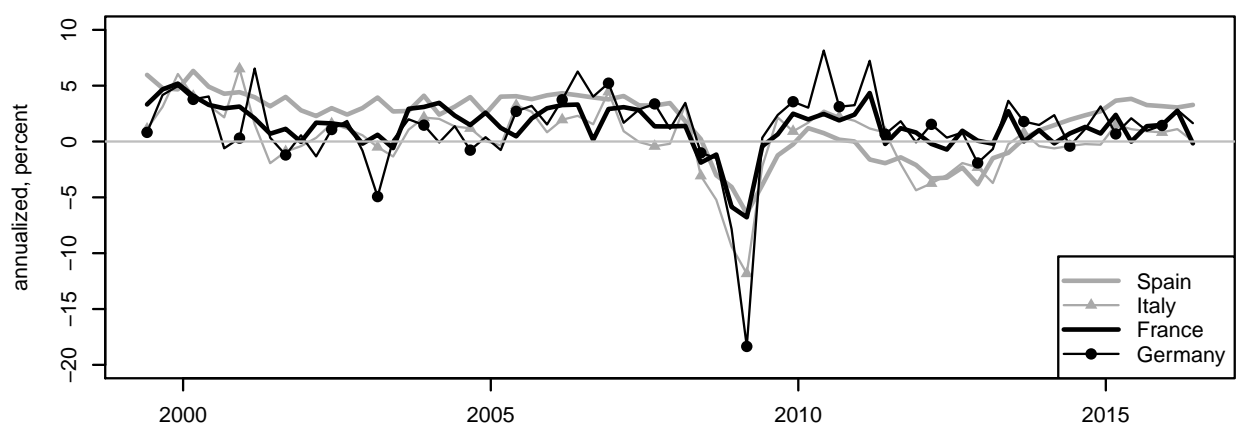

Panel (c) Ex ante real rate

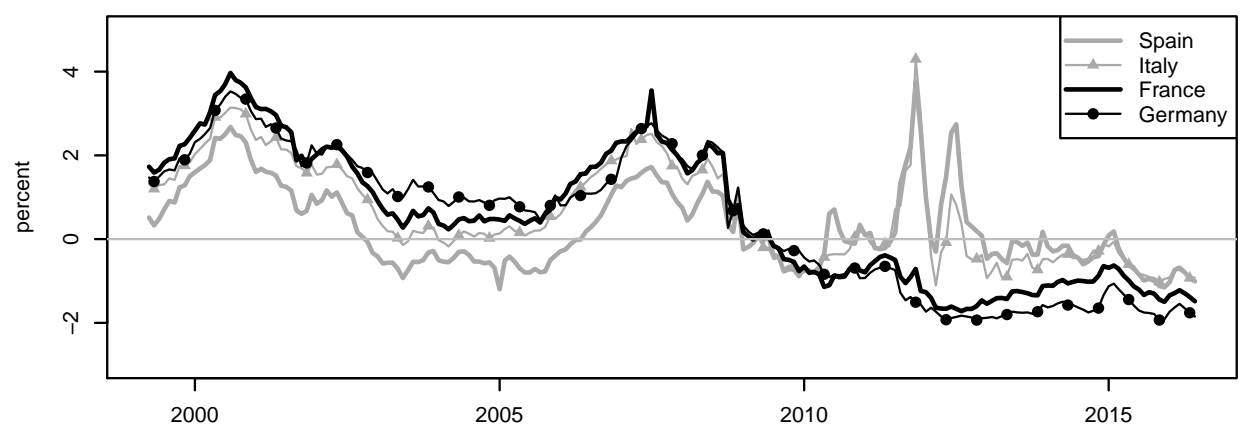

Upper panel: monthly year-on-year core inflation rate. Middle panel: quarterly GDP growth rate (annualized). Lower panel: ex ante one-year real rate of interest. 


\section{E Additional results}

\section{Figure E.1: Potential vs actual output growth and changes in output gap}

vs ESI.
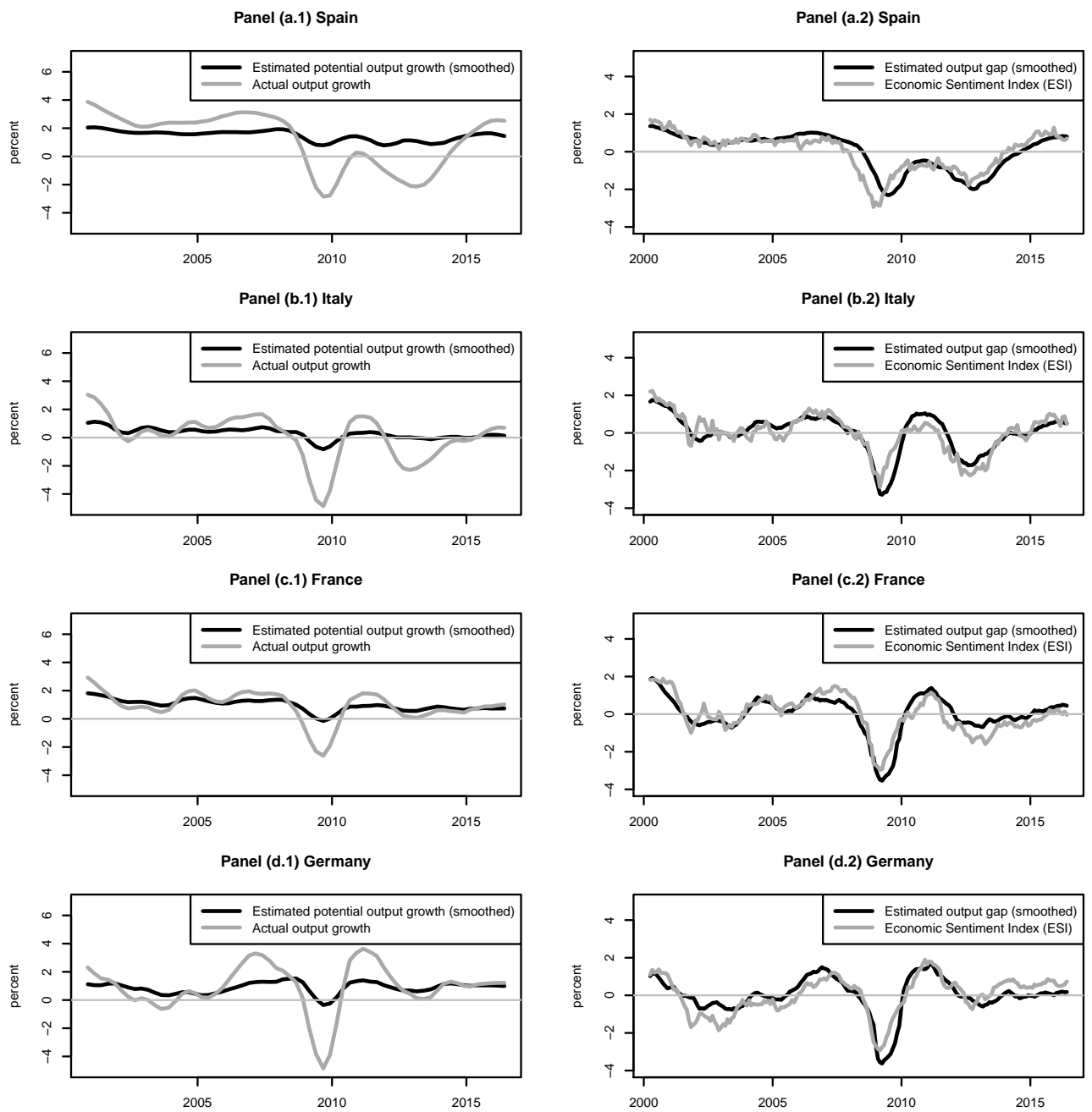

Note: Estimated potential output growth and actual output growth (first column) are expressed as the growth rates of annual averages in percent (i.e., cumulated flows of the last four quarters compared to the cumulated flows of the preceding four quarters). Panels in column 2 compare for each country (normalized) 12-month changes in the estimated output gap with the (normalized) level of Eurostat's Economic Sentiment Indicator (ESI) for this country. 


\section{F Robustness}

Table F.1: Parameter estimates for three different calibrations of $\theta_{j}: 3$, baseline (country-specific, between 3.5 and 3.9) and 5 .

\begin{tabular}{|c|c|c|c|c|c|c|c|c|c|c|c|c|}
\hline & & Germany & & & France & & & Italy & & & Spain & \\
\hline$\gamma$ & $\begin{array}{l}\theta=3 \\
-0.40 \\
(-6.30)\end{array}$ & $\begin{array}{c}\theta=\text { basel. } \\
-0.43 \\
(-6.68)\end{array}$ & $\begin{array}{l}\theta=5 \\
-0.44 \\
(-6.90)\end{array}$ & $\begin{array}{c}\theta=3 \\
-0.00 \\
(-0.04)\end{array}$ & $\begin{array}{c}\theta=\text { basel. } \\
-0.00 \\
(-0.04)\end{array}$ & $\begin{array}{c}\theta=5 \\
-0.01 \\
(-0.15)\end{array}$ & $\begin{array}{c}\theta=3 \\
-0.08 \\
(-1.09)\end{array}$ & $\begin{array}{c}\theta=\text { basel. } \\
-0.07 \\
(-1.03)\end{array}$ & $\begin{array}{c}\theta=5 \\
-0.07 \\
(-1.05)\end{array}$ & $\begin{array}{c}\theta=3 \\
0.36 \\
(5.43)\end{array}$ & $\begin{array}{c}\theta=\text { basel. } \\
0.39 \\
(5.83)\end{array}$ & $\begin{array}{c}\theta=5 \\
0.39 \\
(5.88)\end{array}$ \\
\hline$\beta$ & $\begin{array}{c}0.01 \\
(0.39)\end{array}$ & $\begin{array}{c}0.26 \\
(2.05)\end{array}$ & $\begin{array}{c}0.29 \\
(2.63)\end{array}$ & $\begin{array}{c}0.32 \\
(2.74)\end{array}$ & $\begin{array}{c}0.36 \\
(2.50)\end{array}$ & $\begin{array}{c}0.36 \\
(2.60)\end{array}$ & $\begin{array}{c}0.20 \\
(4.18)\end{array}$ & $\begin{array}{c}0.20 \\
(3.87)\end{array}$ & $\begin{array}{c}0.19 \\
(4.01)\end{array}$ & $\begin{array}{c}0.09 \\
(3.89)\end{array}$ & $\begin{array}{c}0.08 \\
(3.21)\end{array}$ & $\begin{array}{c}0.07 \\
(3.19)\end{array}$ \\
\hline$\sigma_{\pi}$ & $\begin{array}{c}1.75 \\
(20.34)\end{array}$ & $\begin{array}{c}1.70 \\
(19.23)\end{array}$ & $\begin{array}{c}1.69 \\
(19.54)\end{array}$ & $\begin{array}{c}1.38 \\
(20.17)\end{array}$ & $\begin{array}{c}1.38 \\
(19.98)\end{array}$ & $\begin{array}{c}1.37 \\
(19.97)\end{array}$ & $\begin{array}{c}1.31 \\
(20.08)\end{array}$ & $\begin{array}{c}1.31 \\
(19.99)\end{array}$ & $\begin{array}{c}1.31 \\
(20.00)\end{array}$ & $\begin{array}{c}1.56 \\
(20.18)\end{array}$ & $\begin{array}{c}1.58 \\
(20.15)\end{array}$ & $\begin{array}{c}1.58 \\
(20.16)\end{array}$ \\
\hline$\alpha$ & $\begin{array}{c}1.01 \\
(114.82)\end{array}$ & $\begin{array}{c}0.97 \\
(44.46)\end{array}$ & $\begin{array}{c}0.96 \\
(47.67)\end{array}$ & $\begin{array}{c}0.98 \\
(35.66)\end{array}$ & $\begin{array}{c}0.96 \\
(17.99)\end{array}$ & $\begin{array}{c}0.95 \\
(18.15)\end{array}$ & $\begin{array}{c}0.98 \\
(66.93)\end{array}$ & $\begin{array}{c}1.01 \\
(47.05)\end{array}$ & $\begin{array}{c}1.01 \\
(55.30)\end{array}$ & $\begin{array}{c}0.98 \\
(160.79)\end{array}$ & $\begin{array}{c}0.98 \\
(152.18)\end{array}$ & $\begin{array}{c}0.98 \\
(146.46)\end{array}$ \\
\hline$\delta$ & $\begin{array}{c}0.34 \\
(2.31)\end{array}$ & $\begin{array}{c}0.51 \\
(2.66)\end{array}$ & $\begin{array}{c}0.51 \\
(2.87)\end{array}$ & $\begin{array}{c}0.34 \\
(2.41)\end{array}$ & $\begin{array}{c}0.38 \\
(1.28)\end{array}$ & $\begin{array}{c}0.42 \\
(1.43)\end{array}$ & $\begin{array}{c}0.47 \\
(2.26)\end{array}$ & $\begin{array}{c}0.10 \\
(0.31)\end{array}$ & $\begin{array}{c}0.09 \\
(0.33)\end{array}$ & $\begin{array}{c}0.81 \\
(4.57)\end{array}$ & $\begin{array}{c}0.75 \\
(3.76)\end{array}$ & $\begin{array}{c}0.73 \\
(3.66)\end{array}$ \\
\hline$\lambda$ & $\begin{array}{l}-0.12 \\
(-4.74)\end{array}$ & $\begin{array}{c}-0.13 \\
(-4.34)\end{array}$ & $\begin{array}{c}-0.13 \\
(-4.48)\end{array}$ & $\begin{array}{c}-0.09 \\
(-4.68)\end{array}$ & $\begin{array}{c}-0.10 \\
(-4.56)\end{array}$ & $\begin{array}{l}-0.10 \\
(-4.96)\end{array}$ & $\begin{array}{c}-0.12 \\
(-6.69)\end{array}$ & $\begin{array}{c}-0.13 \\
(-6.67)\end{array}$ & $\begin{array}{c}-0.13 \\
(-6.92)\end{array}$ & $\begin{array}{c}-0.13 \\
(-8.91)\end{array}$ & $\begin{array}{c}-0.14 \\
(-9.16)\end{array}$ & $\begin{array}{l}-0.15 \\
(-9.58)\end{array}$ \\
\hline$\psi$ & $\begin{array}{c}0.88 \\
(22.26)\end{array}$ & $\begin{array}{c}0.91 \\
(28.91)\end{array}$ & $\begin{array}{c}0.91 \\
(29.88)\end{array}$ & $\begin{array}{c}0.92 \\
(36.60)\end{array}$ & $\begin{array}{c}0.94 \\
(50.35)\end{array}$ & $\begin{array}{c}0.94 \\
(56.83)\end{array}$ & $\begin{array}{c}0.92 \\
(37.61)\end{array}$ & $\begin{array}{c}0.92 \\
(39.92)\end{array}$ & $\begin{array}{c}0.92 \\
(40.96)\end{array}$ & $\begin{array}{c}0.94 \\
(62.85)\end{array}$ & $\begin{array}{c}0.95 \\
(69.80)\end{array}$ & $\begin{array}{c}0.95 \\
(72.36)\end{array}$ \\
\hline$\varphi_{\mathrm{IPI}}$ & $\begin{array}{c}2.15 \\
(7.41)\end{array}$ & $\begin{array}{c}2.13 \\
(7.34)\end{array}$ & $\begin{array}{c}2.13 \\
(7.35)\end{array}$ & $\begin{array}{c}3.00 \\
(5.32)\end{array}$ & $\begin{array}{c}3.05 \\
(5.41)\end{array}$ & $\begin{array}{c}3.05 \\
(5.41)\end{array}$ & $\begin{array}{c}2.87 \\
(9.10)\end{array}$ & $\begin{array}{c}2.87 \\
(9.18)\end{array}$ & $\begin{array}{c}2.87 \\
(9.18)\end{array}$ & $\begin{array}{c}1.67 \\
(4.40)\end{array}$ & $\begin{array}{c}1.66 \\
(4.38)\end{array}$ & $\begin{array}{c}1.66 \\
(4.39)\end{array}$ \\
\hline$\mu_{\text {IPI }}$ & $\begin{array}{l}-1.30 \\
(-1.22)\end{array}$ & $\begin{array}{l}-1.16 \\
(-1.08)\end{array}$ & $\begin{array}{l}-1.16 \\
(-1.08)\end{array}$ & $\begin{array}{c}-4.47 \\
(-3.39)\end{array}$ & $\begin{array}{c}-4.61 \\
(-3.51)\end{array}$ & $\begin{array}{c}-4.61 \\
(-3.52)\end{array}$ & $\begin{array}{c}-1.97 \\
(-2.16)\end{array}$ & $\begin{array}{l}-1.93 \\
(-2.13)\end{array}$ & $\begin{array}{c}-1.93 \\
(-2.13)\end{array}$ & $\begin{array}{c}-3.67 \\
(-2.89)\end{array}$ & $\begin{array}{l}-3.76 \\
(-2.96)\end{array}$ & $\begin{array}{c}-3.76 \\
(-2.97)\end{array}$ \\
\hline$\sigma_{\text {IPI }}$ & $\begin{array}{c}14.42 \\
(15.86)\end{array}$ & $\begin{array}{c}14.40 \\
(15.69)\end{array}$ & $\begin{array}{c}14.39 \\
(15.65)\end{array}$ & $\begin{array}{c}15.42 \\
(16.87)\end{array}$ & $\begin{array}{c}15.34 \\
(16.49)\end{array}$ & $\begin{array}{c}15.31 \\
(16.34)\end{array}$ & $\begin{array}{c}13.04 \\
(14.71)\end{array}$ & $\begin{array}{c}12.96 \\
(14.46)\end{array}$ & $\begin{array}{c}12.96 \\
(14.47)\end{array}$ & $\begin{array}{c}15.36 \\
(19.59)\end{array}$ & $\begin{array}{c}15.35 \\
(19.54)\end{array}$ & $\begin{array}{c}15.34 \\
(19.51)\end{array}$ \\
\hline$\sigma_{y}$ & $\begin{array}{c}2.05 \\
(9.22)\end{array}$ & $\begin{array}{c}2.08 \\
(9.39)\end{array}$ & $\begin{array}{c}2.09 \\
(9.45)\end{array}$ & $\begin{array}{c}1.15 \\
(9.22)\end{array}$ & $\begin{array}{c}1.18 \\
(9.00)\end{array}$ & $\begin{array}{c}1.19 \\
(8.95)\end{array}$ & $\begin{array}{c}1.63 \\
(9.32)\end{array}$ & $\begin{array}{c}1.68 \\
(9.38)\end{array}$ & $\begin{array}{c}1.68 \\
(9.37)\end{array}$ & $\begin{array}{c}1.21 \\
(8.20)\end{array}$ & $\begin{array}{c}1.25 \\
(8.18)\end{array}$ & $\begin{array}{c}1.27 \\
(8.28)\end{array}$ \\
\hline
\end{tabular}

Student- $t$ statistics in parenthesis.

Table F.2: Estimated correlation matrix of national NRI shocks for three different calibrations of $\theta_{j}$ : 3, baseline (country-specific, between 3.5 and $3.9)$ and 5.

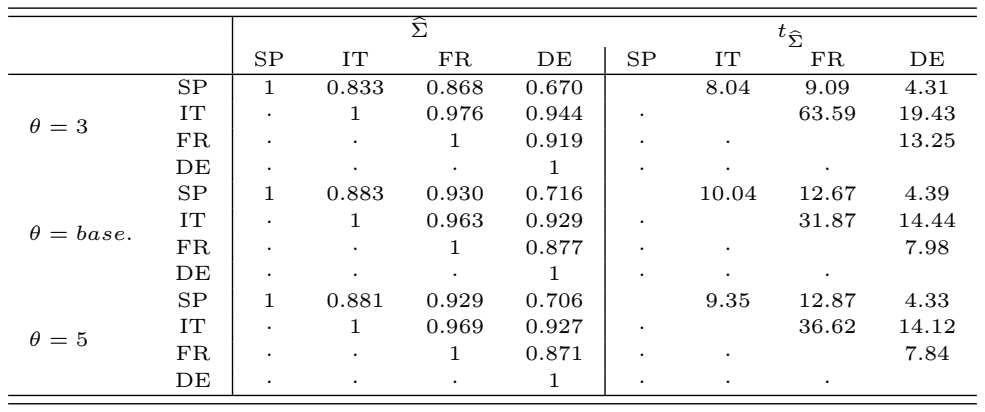


Table F.3: Parameter estimates for three different lags of the real interest gap in the IS equations: 1 month, 2 months (baseline), 3 months.

\begin{tabular}{|c|c|c|c|c|c|c|c|c|c|c|c|c|}
\hline & \multicolumn{3}{|c|}{ Germany } & \multicolumn{3}{|c|}{ France } & \multicolumn{3}{|c|}{ Italy } & \multicolumn{3}{|c|}{ Spain } \\
\hline & Lag 1 & Lag 2 & Lag 3 & Lag 1 & Lag 2 & Lag 3 & Lag 1 & Lag 2 & Lag 3 & Lag 1 & Lag 2 & Lag 3 \\
\hline$\gamma$ & $\begin{array}{l}-0.43 \\
(-6.62)\end{array}$ & $\begin{array}{l}-0.43 \\
(-6.68)\end{array}$ & $\begin{array}{l}-0.44 \\
(-6.74)\end{array}$ & $\begin{array}{l}-0.00 \\
(-0.04)\end{array}$ & $\begin{array}{l}-0.00 \\
(-0.04)\end{array}$ & $\begin{array}{l}-0.00 \\
(-0.01)\end{array}$ & $\begin{array}{l}-0.07 \\
(-1.01)\end{array}$ & $\begin{array}{c}-0.07 \\
(-1.03)\end{array}$ & $\begin{array}{l}-0.07 \\
(-1.05)\end{array}$ & $\begin{array}{c}0.39 \\
(5.83)\end{array}$ & $\begin{array}{c}0.39 \\
(5.83)\end{array}$ & $\begin{array}{c}0.39 \\
(5.90)\end{array}$ \\
\hline$\beta$ & $\begin{array}{c}0.26 \\
(1.90)\end{array}$ & $\begin{array}{c}0.26 \\
(2.05)\end{array}$ & $\begin{array}{c}0.27 \\
(2.18)\end{array}$ & $\begin{array}{c}0.39 \\
(2.39)\end{array}$ & $\begin{array}{c}0.36 \\
(2.50)\end{array}$ & $\begin{array}{c}0.35 \\
(2.52)\end{array}$ & $\begin{array}{c}0.20 \\
(4.01)\end{array}$ & $\begin{array}{c}0.20 \\
(3.87)\end{array}$ & $\begin{array}{c}0.20 \\
(3.77)\end{array}$ & $\begin{array}{c}0.08 \\
(3.20)\end{array}$ & $\begin{array}{c}0.08 \\
(3.21)\end{array}$ & $\begin{array}{c}0.07 \\
(3.17)\end{array}$ \\
\hline$\sigma_{\pi}$ & $\begin{array}{c}1.70 \\
(19.09)\end{array}$ & $\begin{array}{c}1.70 \\
(19.23)\end{array}$ & $\begin{array}{c}1.70 \\
(19.34)\end{array}$ & $\begin{array}{c}1.38 \\
(19.91)\end{array}$ & $\begin{array}{c}1.38 \\
(19.98)\end{array}$ & $\begin{array}{c}1.38 \\
(20.00)\end{array}$ & $\begin{array}{c}1.32 \\
(20.02)\end{array}$ & $\begin{array}{c}1.31 \\
(19.99)\end{array}$ & $\begin{array}{c}1.31 \\
(19.97)\end{array}$ & $\begin{array}{c}1.58 \\
(20.14)\end{array}$ & $\begin{array}{c}1.58 \\
(20.15)\end{array}$ & $\begin{array}{c}1.58 \\
(20.18)\end{array}$ \\
\hline$\alpha$ & $\begin{array}{c}0.97 \\
(43.16)\end{array}$ & $\begin{array}{c}0.97 \\
(44.46)\end{array}$ & $\begin{array}{c}0.97 \\
(47.21)\end{array}$ & $\begin{array}{c}0.96 \\
(15.95)\end{array}$ & $\begin{array}{c}0.96 \\
(17.99)\end{array}$ & $\begin{array}{c}0.95 \\
(19.15)\end{array}$ & $\begin{array}{c}1.01 \\
(45.11)\end{array}$ & $\begin{array}{c}1.01 \\
(47.05)\end{array}$ & $\begin{array}{c}1.01 \\
(57.01)\end{array}$ & $\begin{array}{c}0.98 \\
(147.73)\end{array}$ & $\begin{array}{c}0.98 \\
(152.18)\end{array}$ & $\begin{array}{c}0.98 \\
(154.22)\end{array}$ \\
\hline$\delta$ & $\begin{array}{c}0.50 \\
(2.69)\end{array}$ & $\begin{array}{c}0.51 \\
(2.66)\end{array}$ & $\begin{array}{c}0.49 \\
(2.76)\end{array}$ & $\begin{array}{c}0.36 \\
(1.21)\end{array}$ & $\begin{array}{c}0.38 \\
(1.28)\end{array}$ & $\begin{array}{c}0.37 \\
(1.32)\end{array}$ & $\begin{array}{c}0.11 \\
(0.31)\end{array}$ & $\begin{array}{c}0.10 \\
(0.31)\end{array}$ & $\begin{array}{c}0.05 \\
(0.17)\end{array}$ & $\begin{array}{c}0.77 \\
(3.60)\end{array}$ & $\begin{array}{c}0.75 \\
(3.76)\end{array}$ & $\begin{array}{c}0.74 \\
(3.83)\end{array}$ \\
\hline$\lambda$ & $\begin{array}{l}-0.13 \\
(-4.47)\end{array}$ & $\begin{array}{l}-0.13 \\
(-4.34)\end{array}$ & $\begin{array}{c}-0.12 \\
(-4.26)\end{array}$ & $\begin{array}{l}-0.09 \\
(-4.55)\end{array}$ & $\begin{array}{l}-0.10 \\
(-4.56)\end{array}$ & $\begin{array}{l}-0.09 \\
(-4.49)\end{array}$ & $\begin{array}{l}-0.13 \\
(-6.71)\end{array}$ & $\begin{array}{c}-0.13 \\
(-6.67)\end{array}$ & $\begin{array}{l}-0.12 \\
(-6.59)\end{array}$ & $\begin{array}{l}-0.14 \\
(-8.47)\end{array}$ & $\begin{array}{c}-0.14 \\
(-9.16)\end{array}$ & $\begin{array}{c}-0.14 \\
(-9.54)\end{array}$ \\
\hline$\psi$ & $\begin{array}{c}0.91 \\
(28.27)\end{array}$ & $\begin{array}{c}0.91 \\
(28.91)\end{array}$ & $\begin{array}{c}0.91 \\
(28.12)\end{array}$ & $\begin{array}{c}0.94 \\
(47.15)\end{array}$ & $\begin{array}{c}0.94 \\
(50.35)\end{array}$ & $\begin{array}{c}0.94 \\
(50.33)\end{array}$ & $\begin{array}{c}0.92 \\
(40.66)\end{array}$ & $\begin{array}{c}0.92 \\
(39.92)\end{array}$ & $\begin{array}{c}0.92 \\
(38.47)\end{array}$ & $\begin{array}{c}0.94 \\
(68.13)\end{array}$ & $\begin{array}{c}0.95 \\
(69.80)\end{array}$ & $\begin{array}{c}0.95 \\
(71.21)\end{array}$ \\
\hline$\varphi_{\mathrm{IPI}}$ & $\begin{array}{c}2.12 \\
(7.28)\end{array}$ & $\begin{array}{c}2.13 \\
(7.34)\end{array}$ & $\begin{array}{c}2.13 \\
(7.32)\end{array}$ & $\begin{array}{c}3.03 \\
(5.34)\end{array}$ & $\begin{array}{c}3.05 \\
(5.41)\end{array}$ & $\begin{array}{c}3.02 \\
(5.30)\end{array}$ & $\begin{array}{c}2.80 \\
(8.57)\end{array}$ & $\begin{array}{c}2.87 \\
(9.18)\end{array}$ & $\begin{array}{c}2.80 \\
(8.57)\end{array}$ & $\begin{array}{c}1.55 \\
(4.05)\end{array}$ & $\begin{array}{c}1.66 \\
(4.38)\end{array}$ & $\begin{array}{c}1.63 \\
(4.30)\end{array}$ \\
\hline$\mu_{\mathrm{IPI}}$ & $\begin{array}{l}-1.18 \\
(-1.09)\end{array}$ & $\begin{array}{l}-1.16 \\
(-1.08)\end{array}$ & $\begin{array}{l}-1.16 \\
(-1.08)\end{array}$ & $\begin{array}{l}-4.68 \\
(-3.56)\end{array}$ & $\begin{array}{l}-4.61 \\
(-3.51)\end{array}$ & $\begin{array}{l}-4.60 \\
(-3.49)\end{array}$ & $\begin{array}{l}-1.90 \\
(-2.05)\end{array}$ & $\begin{array}{l}-1.93 \\
(-2.13)\end{array}$ & $\begin{array}{l}-1.92 \\
(-2.09)\end{array}$ & $\begin{array}{c}-3.57 \\
(-2.79)\end{array}$ & $\begin{array}{l}-3.76 \\
(-2.96)\end{array}$ & $\begin{array}{l}-3.75 \\
(-2.95)\end{array}$ \\
\hline$\sigma_{\mathrm{IPI}}$ & $\begin{array}{c}14.46 \\
(15.86)\end{array}$ & $\begin{array}{c}14.40 \\
(15.69)\end{array}$ & $\begin{array}{c}14.37 \\
(15.46)\end{array}$ & $\begin{array}{c}15.40 \\
(16.56)\end{array}$ & $\begin{array}{c}15.34 \\
(16.49)\end{array}$ & $\begin{array}{c}15.38 \\
(16.46)\end{array}$ & $\begin{array}{c}13.27 \\
(15.01)\end{array}$ & $\begin{array}{c}12.96 \\
(14.46)\end{array}$ & $\begin{array}{c}13.18 \\
(14.49)\end{array}$ & $\begin{array}{c}15.47 \\
(19.65)\end{array}$ & $\begin{array}{c}15.35 \\
(19.54)\end{array}$ & $\begin{array}{c}15.41 \\
(19.70)\end{array}$ \\
\hline$\sigma_{y}$ & $\begin{array}{c}2.04 \\
(9.23)\end{array}$ & $\begin{array}{c}2.08 \\
(9.39)\end{array}$ & $\begin{array}{c}2.13 \\
(9.56)\end{array}$ & $\begin{array}{c}1.18 \\
(8.83)\end{array}$ & $\begin{array}{c}1.18 \\
(9.00)\end{array}$ & $\begin{array}{c}1.20 \\
(9.22)\end{array}$ & $\begin{array}{c}1.60 \\
(9.06)\end{array}$ & $\begin{array}{c}1.68 \\
(9.38)\end{array}$ & $\begin{array}{c}1.70 \\
(9.48)\end{array}$ & $\begin{array}{c}1.24 \\
(7.81)\end{array}$ & $\begin{array}{c}1.25 \\
(8.18)\end{array}$ & $\begin{array}{c}1.17 \\
(8.07)\end{array}$ \\
\hline
\end{tabular}

Student- $t$ statistics in parenthesis.

Table F.4: Estimated correlation matrix of national NRI shocks for three different lags of the interest gap in the IS equations: 1 month, 2 months (baseline), 3 months

\begin{tabular}{ll|cccc|cccc}
\hline \hline & & \multicolumn{9}{|c}{$\widehat{\Sigma}$} & \multicolumn{3}{c}{$t_{\widehat{\Sigma}}$} \\
& & SP & IT & FR & DE & SP & IT & FR & DE \\
\hline \multirow{4}{*}{ Lag 1 } & SP & 1 & 0.868 & 0.918 & 0.705 & & 7.07 & 7.50 & 3.66 \\
& IT &. & 1 & 0.972 & 0.940 &. & & 30.63 & 16.85 \\
& FR &. &. & 1 & 0.897 &. &. & & 8.05 \\
& DE &. &. &. & 1 &. &. &. & \\
& SP & 1 & 0.883 & 0.930 & 0.716 & & 10.04 & 12.67 & 4.39 \\
\multirow{2}{*}{ Lag 2 } & IT &. & 1 & 0.963 & 0.929 &. & & 31.87 & 14.44 \\
& FR &. &. & 1 & 0.877 &. &. & & 7.98 \\
& DE &. &. &. & 1 &. &. &. & \\
& SP & 1 & 0.879 & 0.916 & 0.677 & & 9.47 & 11.50 & 4.01 \\
\multirow{2}{*}{ Lag 3 3} & IT &. & 1 & 0.973 & 0.915 &. & & 45.38 & 12.08 \\
& FR &. &. & 1 & 0.868 &. &. & & 7.28 \\
& DE &. &. &. & 1 &. &. &. & \\
\hline
\end{tabular}


Table F.5: Parameter estimates for three different calibrations of $\sigma_{z} / \sigma_{y}$ : 1(baseline), 1.5 and 2.

\begin{tabular}{|c|c|c|c|c|c|c|c|c|c|c|c|c|}
\hline & \multicolumn{3}{|c|}{ Germany } & \multicolumn{3}{|c|}{ France } & \multicolumn{3}{|c|}{ Italy } & \multicolumn{3}{|c|}{ Spain } \\
\hline & $\frac{\sigma_{z}}{\sigma_{y}}=1$ & $\frac{\sigma_{z}}{\sigma_{y}}=1.5$ & $\frac{\sigma_{z}}{\sigma_{y}}=2$ & $\frac{\sigma_{z}}{\sigma_{y}}=1$ & $\frac{\sigma_{z}}{\sigma_{y}}=1.5$ & $\frac{\sigma_{z}}{\sigma_{y}}=2$ & $\frac{\sigma_{z}}{\sigma_{y}}=1$ & $\frac{\sigma_{z}}{\sigma_{y}}=1.5$ & $\frac{\sigma_{z}}{\sigma_{y}}=2$ & $\frac{\sigma_{z}}{\sigma_{y}}=1$ & $\frac{\sigma_{z}}{\sigma_{y}}=1.5$ & $\frac{\sigma_{z}}{\sigma_{y}}=2$ \\
\hline$\gamma$ & $\begin{array}{c}-0.43 \\
(-6.68)\end{array}$ & $\begin{array}{c}-0.40 \\
(-6.31)\end{array}$ & $\begin{array}{l}-0.40 \\
(-6.32)\end{array}$ & $\begin{array}{c}-0.00 \\
(-0.04)\end{array}$ & $\begin{array}{c}-0.00 \\
(-0.05)\end{array}$ & $\begin{array}{c}-0.00 \\
(-0.03)\end{array}$ & $\begin{array}{c}-0.07 \\
(-1.03)\end{array}$ & $\begin{array}{c}-0.07 \\
(-1.02)\end{array}$ & $\begin{array}{c}-0.07 \\
(-0.97)\end{array}$ & $\begin{array}{c}0.39 \\
(5.83)\end{array}$ & $\begin{array}{c}0.38 \\
(5.66)\end{array}$ & $\begin{array}{c}0.38 \\
(5.78)\end{array}$ \\
\hline$\beta$ & $\begin{array}{c}0.26 \\
(2.05)\end{array}$ & $\begin{array}{c}0.02 \\
(0.57)\end{array}$ & $\begin{array}{c}0.02 \\
(0.63)\end{array}$ & $\begin{array}{c}0.36 \\
(2.50)\end{array}$ & $\begin{array}{c}0.30 \\
(3.02)\end{array}$ & $\begin{array}{c}0.28 \\
(3.23)\end{array}$ & $\begin{array}{c}0.20 \\
(3.87)\end{array}$ & $\begin{array}{c}0.18 \\
(4.61)\end{array}$ & $\begin{array}{c}0.18 \\
(4.88)\end{array}$ & $\begin{array}{c}0.08 \\
(3.21)\end{array}$ & $\begin{array}{c}0.08 \\
(3.66)\end{array}$ & $\begin{array}{c}0.08 \\
(3.56)\end{array}$ \\
\hline$\sigma_{\pi}$ & $\begin{array}{c}1.70 \\
(19.23)\end{array}$ & $\begin{array}{c}1.75 \\
(20.33)\end{array}$ & $\begin{array}{c}1.75 \\
(20.33)\end{array}$ & $\begin{array}{c}1.38 \\
(19.98)\end{array}$ & $\begin{array}{c}1.38 \\
(20.20)\end{array}$ & $\begin{array}{c}1.38 \\
(20.24)\end{array}$ & $\begin{array}{c}1.31 \\
(19.99)\end{array}$ & $\begin{array}{c}1.32 \\
(20.14)\end{array}$ & $\begin{array}{c}1.32 \\
(20.18)\end{array}$ & $\begin{array}{c}1.58 \\
(20.15)\end{array}$ & $\begin{array}{c}1.57 \\
(20.20)\end{array}$ & $\begin{array}{c}1.57 \\
(20.22)\end{array}$ \\
\hline$\alpha$ & $\begin{array}{c}0.97 \\
(44.46)\end{array}$ & $\begin{array}{c}1.00 \\
(98.37)\end{array}$ & $\begin{array}{c}1.00 \\
(96.68)\end{array}$ & $\begin{array}{c}0.96 \\
(17.99)\end{array}$ & $\begin{array}{c}0.97 \\
(34.11)\end{array}$ & $\begin{array}{c}0.97 \\
(36.26)\end{array}$ & $\begin{array}{c}1.01 \\
(47.05)\end{array}$ & $\begin{array}{c}0.98 \\
(65.74)\end{array}$ & $\begin{array}{c}0.98 \\
(65.83)\end{array}$ & $\begin{array}{c}0.98 \\
(152.18)\end{array}$ & $\begin{array}{c}0.98 \\
(172.10)\end{array}$ & $\begin{array}{c}0.98 \\
(177.26)\end{array}$ \\
\hline$\delta$ & $\begin{array}{c}0.51 \\
(2.66)\end{array}$ & $\begin{array}{c}0.34 \\
(2.51)\end{array}$ & $\begin{array}{c}0.35 \\
(2.57)\end{array}$ & $\begin{array}{c}0.38 \\
(1.28)\end{array}$ & $\begin{array}{c}0.36 \\
(2.33)\end{array}$ & $\begin{array}{c}0.36 \\
(2.31)\end{array}$ & $\begin{array}{c}0.10 \\
(0.31)\end{array}$ & $\begin{array}{c}0.47 \\
(2.11)\end{array}$ & $\begin{array}{c}0.47 \\
(2.08)\end{array}$ & $\begin{array}{c}0.75 \\
(3.76)\end{array}$ & $\begin{array}{c}0.75 \\
(4.62)\end{array}$ & $\begin{array}{c}0.72 \\
(4.65)\end{array}$ \\
\hline$\lambda$ & $\begin{array}{c}-0.13 \\
(-4.34)\end{array}$ & $\begin{array}{c}-0.13 \\
(-4.76)\end{array}$ & $\begin{array}{c}-0.13 \\
(-4.70)\end{array}$ & $\begin{array}{l}-0.10 \\
(-4.56)\end{array}$ & $\begin{array}{c}-0.09 \\
(-4.86)\end{array}$ & $\begin{array}{c}-0.09 \\
(-4.84)\end{array}$ & $\begin{array}{c}-0.13 \\
(-6.67)\end{array}$ & $\begin{array}{c}-0.13 \\
(-6.97)\end{array}$ & $\begin{array}{c}-0.13 \\
(-6.98)\end{array}$ & $\begin{array}{c}-0.14 \\
(-9.16)\end{array}$ & $\begin{array}{c}-0.14 \\
(-9.38)\end{array}$ & $\begin{array}{c}-0.14 \\
(-9.55)\end{array}$ \\
\hline$\psi$ & $\begin{array}{c}0.91 \\
(28.91)\end{array}$ & $\begin{array}{c}0.89 \\
(23.02)\end{array}$ & $\begin{array}{c}0.89 \\
(23.11)\end{array}$ & $\begin{array}{c}0.94 \\
(50.35)\end{array}$ & $\begin{array}{c}0.93 \\
(39.14)\end{array}$ & $\begin{array}{c}0.92 \\
(37.98)\end{array}$ & $\begin{array}{c}0.92 \\
(39.92)\end{array}$ & $\begin{array}{c}0.92 \\
(38.40)\end{array}$ & $\begin{array}{c}0.92 \\
(38.01)\end{array}$ & $\begin{array}{c}0.95 \\
(69.80)\end{array}$ & $\begin{array}{c}0.94 \\
(66.32)\end{array}$ & $\begin{array}{c}0.95 \\
(68.40)\end{array}$ \\
\hline$\varphi_{\text {IPI }}$ & $\begin{array}{c}2.13 \\
(7.34)\end{array}$ & $\begin{array}{c}2.14 \\
(7.38)\end{array}$ & $\begin{array}{c}2.15 \\
(7.39)\end{array}$ & $\begin{array}{c}3.05 \\
(5.41)\end{array}$ & $\begin{array}{c}3.08 \\
(5.48)\end{array}$ & $\begin{array}{c}2.98 \\
(5.27)\end{array}$ & $\begin{array}{c}2.87 \\
(9.18)\end{array}$ & $\begin{array}{c}2.87 \\
(9.11)\end{array}$ & $\begin{array}{c}2.87 \\
(9.12)\end{array}$ & $\begin{array}{c}1.66 \\
(4.38)\end{array}$ & $\begin{array}{c}1.67 \\
(4.41)\end{array}$ & $\begin{array}{c}1.65 \\
(4.35)\end{array}$ \\
\hline$\mu_{\mathrm{IPI}}$ & $\begin{array}{l}-1.16 \\
(-1.08)\end{array}$ & $\begin{array}{c}-1.30 \\
(-1.21)\end{array}$ & $\begin{array}{l}-1.30 \\
(-1.21)\end{array}$ & $\begin{array}{l}-4.61 \\
(-3.51)\end{array}$ & $\begin{array}{l}-4.73 \\
(-3.62)\end{array}$ & $\begin{array}{l}-4.41 \\
(-3.34)\end{array}$ & $\begin{array}{l}-1.93 \\
(-2.13)\end{array}$ & $\begin{array}{c}-1.91 \\
(-2.11)\end{array}$ & $\begin{array}{l}-1.94 \\
(-2.13)\end{array}$ & $\begin{array}{l}-3.76 \\
(-2.96)\end{array}$ & $\begin{array}{c}-3.83 \\
(-3.02)\end{array}$ & $\begin{array}{l}-3.70 \\
(-2.91)\end{array}$ \\
\hline$\sigma_{\mathrm{IPI}}$ & $\begin{array}{c}14.40 \\
(15.69)\end{array}$ & $\begin{array}{c}14.43 \\
(15.92)\end{array}$ & $\begin{array}{c}14.44 \\
(15.95)\end{array}$ & $\begin{array}{c}15.34 \\
(16.49)\end{array}$ & $\begin{array}{c}15.36 \\
(16.67)\end{array}$ & $\begin{array}{c}15.40 \\
(16.73)\end{array}$ & $\begin{array}{c}12.96 \\
(14.46)\end{array}$ & $\begin{array}{c}13.01 \\
(14.60)\end{array}$ & $\begin{array}{c}13.01 \\
(14.59)\end{array}$ & $\begin{array}{c}15.35 \\
(19.54)\end{array}$ & $\begin{array}{c}15.35 \\
(19.55)\end{array}$ & $\begin{array}{c}15.36 \\
(19.57)\end{array}$ \\
\hline$\sigma_{y}$ & $\begin{array}{c}2.08 \\
(9.39)\end{array}$ & $\begin{array}{c}1.60 \\
(9.24)\end{array}$ & $\begin{array}{c}1.29 \\
(9.24)\end{array}$ & $\begin{array}{c}1.18 \\
(9.00)\end{array}$ & $\begin{array}{c}0.91 \\
(9.05)\end{array}$ & $\begin{array}{c}0.74 \\
(9.06)\end{array}$ & $\begin{array}{c}1.68 \\
(9.38)\end{array}$ & $\begin{array}{c}1.29 \\
(9.28)\end{array}$ & $\begin{array}{c}1.04 \\
(9.27)\end{array}$ & $\begin{array}{c}1.25 \\
(8.18)\end{array}$ & $\begin{array}{c}0.97 \\
(8.22)\end{array}$ & $\begin{array}{c}0.78 \\
(8.28)\end{array}$ \\
\hline
\end{tabular}

Student- $t$ statistics in parenthesis.

Table F.6: Estimated correlation matrix of national NRI shocks for three different calibrations of $\sigma_{z} / \sigma_{y}: 1$ (baseline), 1.5 and 2 .

\begin{tabular}{|c|c|c|c|c|c|c|c|c|c|}
\hline & & \multicolumn{4}{|c|}{$\hat{\Sigma}$} & \multicolumn{4}{|c|}{$t_{\widehat{\Sigma}}$} \\
\hline & & SP & IT & FR & DE & SP & IT & FR & $\mathrm{DE}$ \\
\hline \multirow{4}{*}{$\frac{\sigma_{z}}{\sigma_{y}}=1$} & SP & 1 & 0.883 & 0.930 & 0.716 & & 10.04 & 12.67 & 4.39 \\
\hline & IT & . & 1 & 0.963 & 0.929 & & & 31.87 & 14.44 \\
\hline & FR & . & . & 1 & 0.877 & . & . & & 7.98 \\
\hline & $\mathrm{DE}$ & . & . & . & 1 & . & . & . & \\
\hline \multirow{4}{*}{$\frac{\sigma_{z}}{\sigma_{y}}=1.5$} & SP & 1 & 0.866 & 0.894 & 0.706 & & 9.33 & 10.55 & 4.69 \\
\hline & IT & . & 1 & 0.973 & 0.937 & & & 56.61 & 17.21 \\
\hline & FR & . & . & 1 & 0.906 & . & . & & 11.60 \\
\hline & $\mathrm{DE}$ & . & . & . & 1 & & . & . & \\
\hline \multirow{4}{*}{$\frac{\sigma_{z}}{\sigma_{y}}=2$} & SP & 1 & 0.869 & 0.895 & 0.693 & & 9.76 & 10.60 & 4.72 \\
\hline & IT & . & 1 & 0.976 & 0.932 & 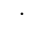 & & 71.94 & 16.39 \\
\hline & FR & . & . & 1 & 0.907 & . & . & & 12.25 \\
\hline & $\mathrm{DE}$ & . & . & . & 1 & & . & . & \\
\hline
\end{tabular}


Figure F.1: Robustness: national real interest rate gaps for $\theta_{j}=1,3,5$ and $\theta_{\text {baseline. }}$
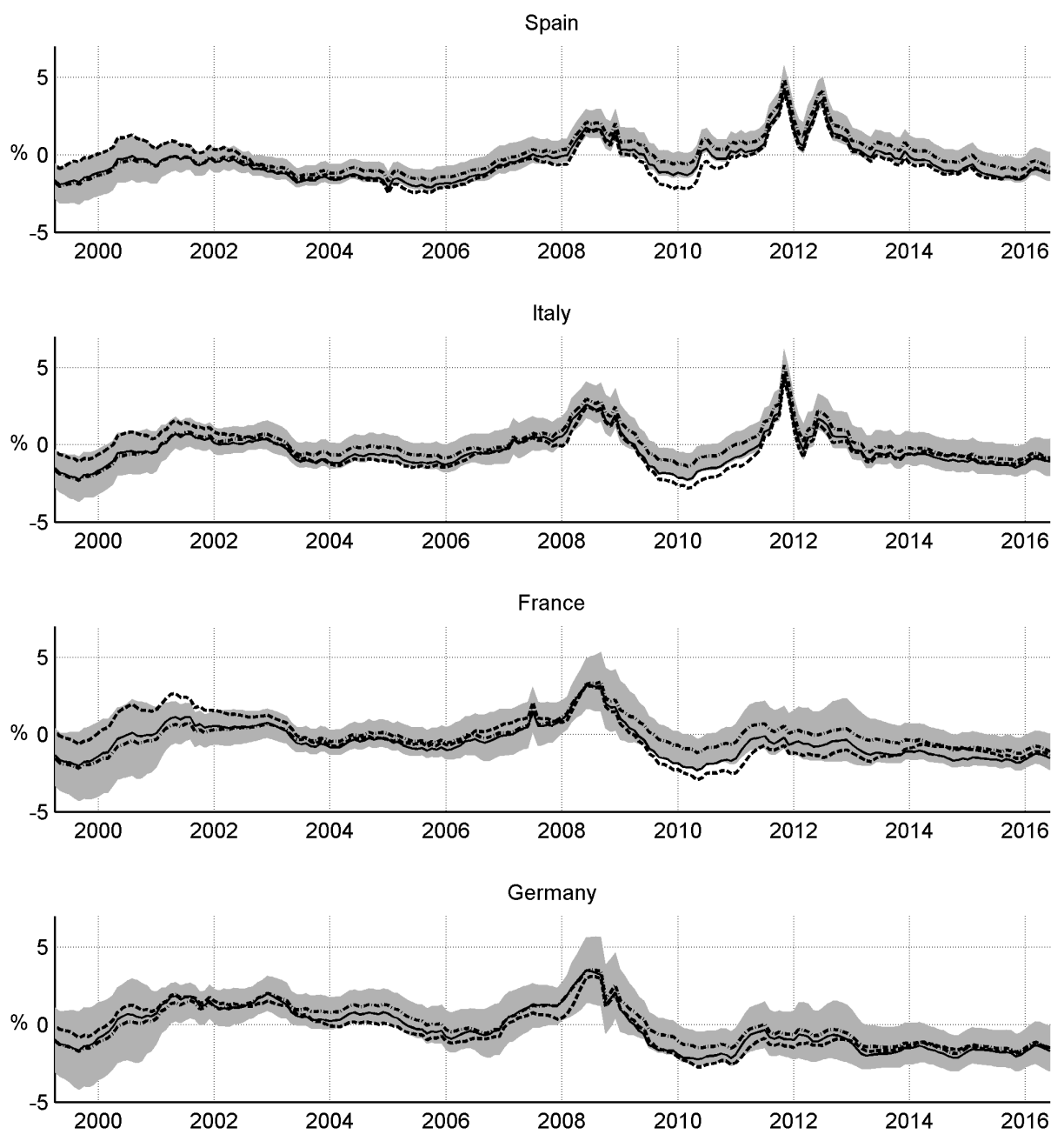

Dashed line: $\theta_{j}=1$, solid line: $\theta_{j}=3$, dotted line: $\theta_{j}=5$, shaded area: $95 \%$ confidence intervals of the baseline estimate with $\sigma_{z} / \sigma_{y}=1$, the IRG lagged by two months and $\theta_{j}=\theta_{\text {baseline. }}$. 
Figure F.2: Robustness: national real interest rate gaps for different lags of the real interest rate gap (IRG) in the IS equation $(1,2$ or 3$)$.

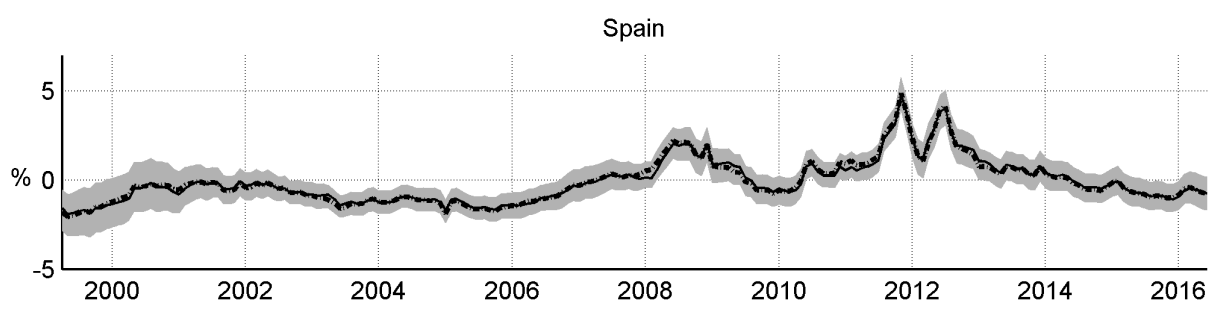

Italy
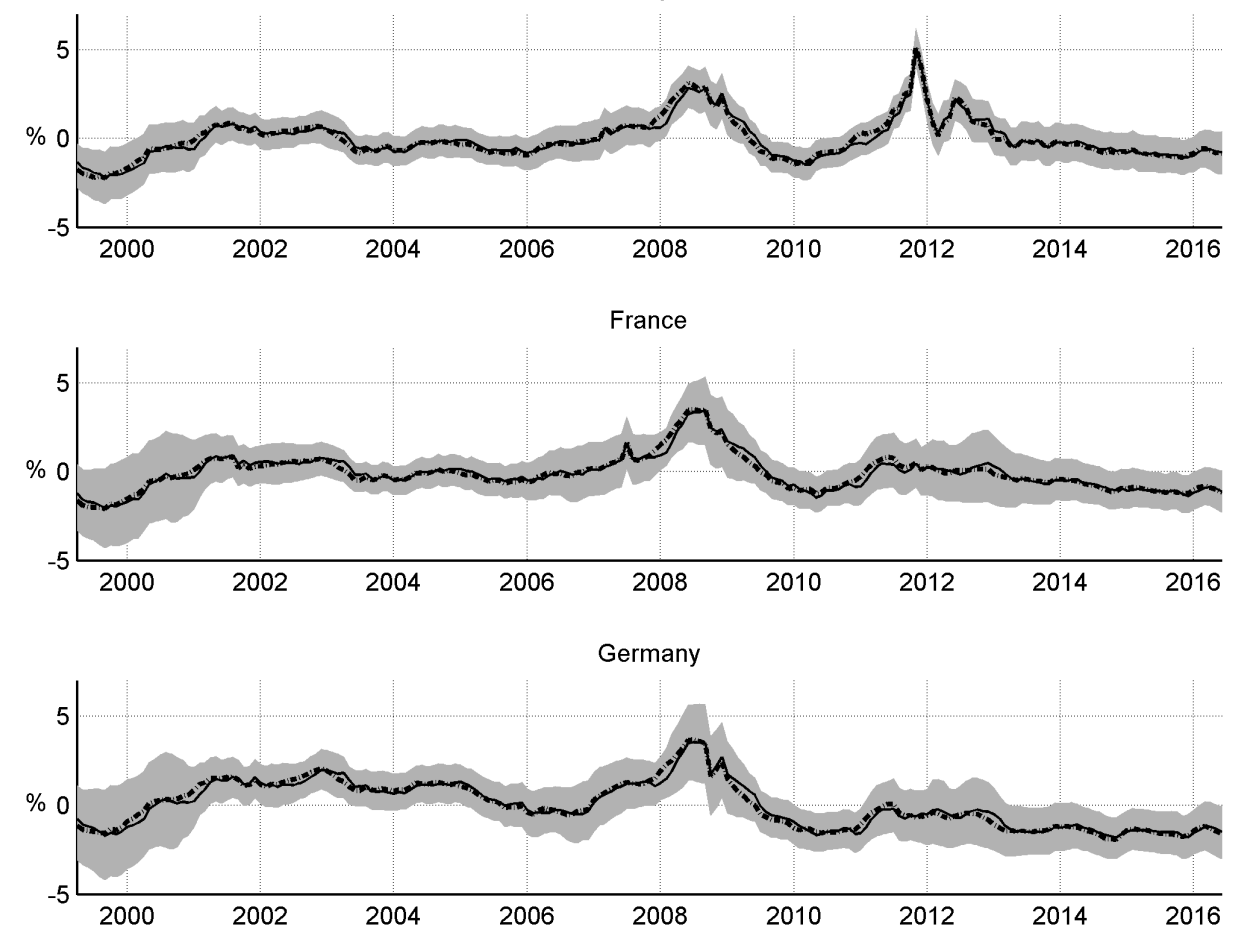

Solid line: IRG lagged by 1 months, dashed line: IRG lagged by 3 months, shaded area: $95 \%$ confidence intervals of the baseline estimate with $\sigma_{z} / \sigma_{y}=1$, the IRG lagged by two months and $\theta_{j}=\theta_{\text {baseline }}$. 
Figure F.3: Robustness: national real interest rate gaps for $\sigma_{z} / \sigma_{y}=1$ (baseline), 1.5, 2.
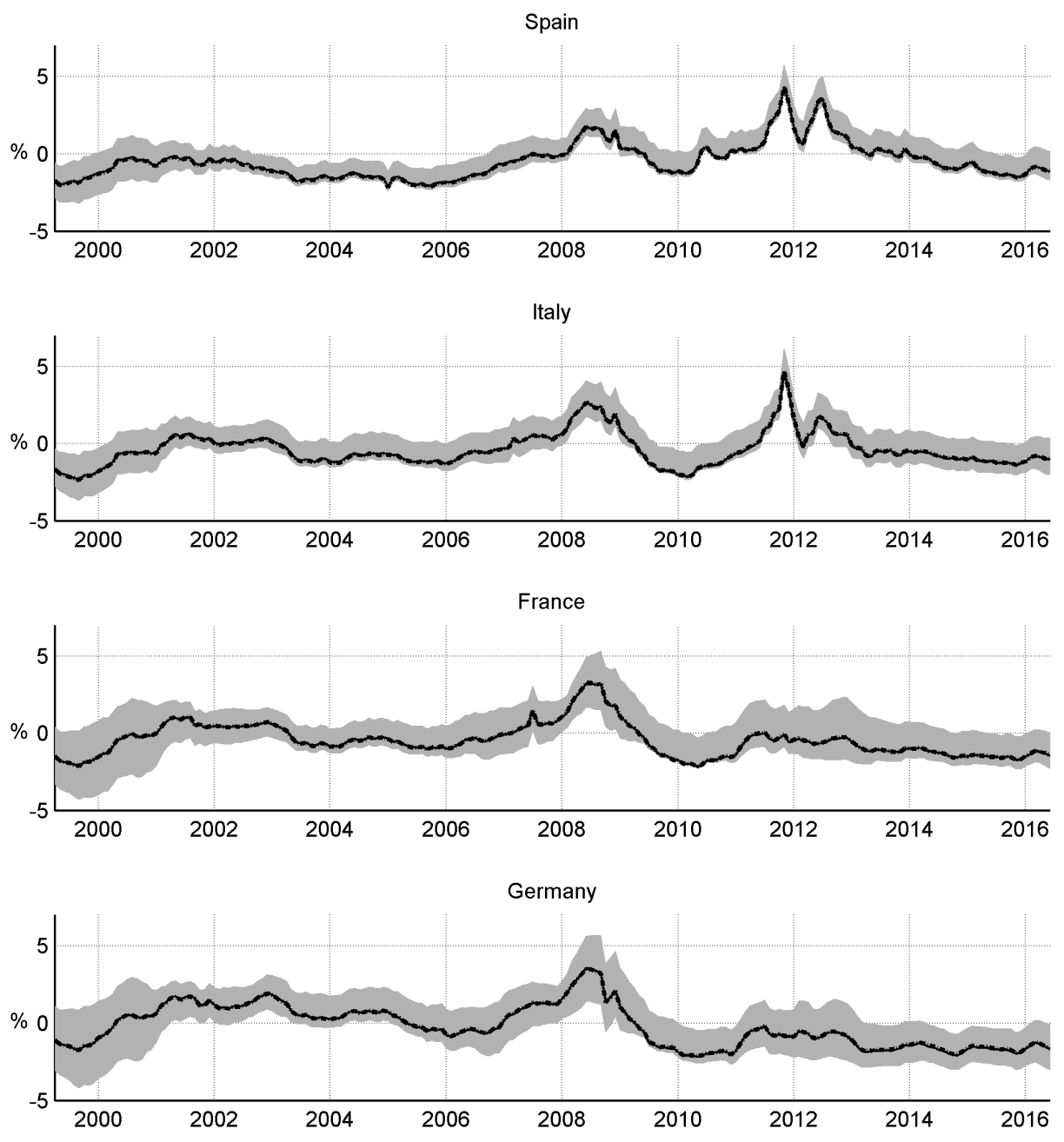

Solid line: $\sigma_{z} / \sigma_{y}=1 ; 5$, dashed line: $\sigma_{z} / \sigma_{y}=2$, shaded area: $95 \%$ confidence intervals of the baseline estimate with $\sigma_{z} / \sigma_{y}=1$, the IRG lagged by two months and $\theta_{j}=\theta_{\text {baseline }}$. 